\title{
Insights on recent approaches in drug discovery strategies and untapped drug targets against drug resistance
}

\author{
Ramalingam Peraman', Sathish Kumar Sure ${ }^{*^{*}}$ (D, V. N. Azger Dusthackeer ${ }^{2}$, Naresh Babu Chilamakuru', \\ Padmanabha Reddy Yiragamreddy ${ }^{1}$, Chiranjeevi Pokuri ${ }^{1}$, Vinay Kumar Kutagulla ${ }^{1}$ and Santhivardhan Chinni ${ }^{1}$
}

\begin{abstract}
Background: Despite the various strategies undertaken in the clinical practice, the mortality rate due to antibioticresistant microbes has been markedly increasing worldwide. In addition to multidrug-resistant (MDR) microbes, the "ESKAPE" bacteria are also emerging. Of course, the infection caused by ESKAPE cannot be treated even with lethal doses of antibiotics. Now, the drug resistance is also more prevalent in antiviral, anticancer, antimalarial and antifungal chemotherapies.

Main body: To date, in the literature, the quantum of research reported on the discovery strategies for new antibiotics is remarkable but the milestone is still far away. Considering the need of the updated strategies and drug discovery approaches in the area of drug resistance among researchers, in this communication, we consolidated the insights pertaining to new drug development against drug-resistant microbes. It includes drug discovery void, gene paradox, transposon mutagenesis, vitamin biosynthesis inhibition, use of non-conventional media, host model, target through quorum sensing, genomic-chemical network, synthetic viability to targets, chemical versus biological space, combinational approach, photosensitization, antimicrobial peptides and transcriptome profiling. Furthermore, we optimally briefed about antievolution drugs, nanotheranostics and antimicrobial adjuvants and then followed by twelve selected new feasible drug targets for new drug design against drug resistance. Finally, we have also tabulated the chemical structures of potent molecules against antimicrobial resistance.
\end{abstract}

Conclusion: It is highly recommended to execute the anti-drug resistance research as integrated approach where both molecular and genetic research needs to be as integrative objective of drug discovery. This is time to accelerate new drug discovery research with advanced genetic approaches instead of conventional blind screening.

Keywords: Antimicrobial resistance, ESKAPE bacteria, Antievolution drugs, Drug resistance, Genomic-chemical network, Drug targets

\footnotetext{
* Correspondence: sathishsure7@gmail.com

${ }^{1}$ RERDS-CPR, Raghavendra Institute of Pharmaceutical Education and

Research (RIPER)-Autonomous, Anantapur, Andhra Pradesh, India

Full list of author information is available at the end of the article
}

\section{Springer Open}

(c) The Author(s). 2021 Open Access This article is licensed under a Creative Commons Attribution 4.0 International License, which permits use, sharing, adaptation, distribution and reproduction in any medium or format, as long as you give appropriate credit to the original author(s) and the source, provide a link to the Creative Commons licence, and indicate if changes were made. The images or other third party material in this article are included in the article's Creative Commons licence, unless indicated otherwise in a credit line to the material. If material is not included in the article's Creative Commons licence and your intended use is not permitted by statutory regulation or exceeds the permitted use, you will need to obtain permission directly from the copyright holder. To view a copy of this licence, visit http://creativecommons.org/licenses/by/4.0/. 


\section{Background}

The term "drug resistance," more commonly referred to medications such as antibiotics, is now extended to anticancer agents. The drug-resistant infectious diseases, including multidrug-resistant (MDR)/ extensively drug-resistant (XDR)-tuberculosis, infection due to methicillin-resistant Staphylococcus aureus (MRSA), vancomycin-resistant Staphylococcus aureus (VRSA), carbapenem-resistant Enterobacteriaceae (CRE), drugresistant Clostridium difficile and drug-resistant cancer are the most life-threatening health issues, which need prioritized focus in research $[1,2]$. Recently, in addition to multidrug-resistant (MDR) pathogens, "ESKAPE" (Enterococcus faecium, Staphylococcus aureus, Klebsiella pneumoniae, Acinetobacter baumannii, Pseudomonas aeruginosa and Enterobacter species) bacteria has also emerged which can withstand lethal doses of all antibiotics. The World Health Organization (WHO) predicted that antimicrobial resistance (AMR) is expected to cause 10 million deaths annually by 2050 [3].

\section{Underlying reasons for drug resistance}

In addition to the drug-resistant bacterial and mycobacterial infections, drug-resistant cancer and drugresistant protozoa, fungal and viral infections are also more prevalent; thus, the hope on successful chemotherapy for these diseases is not optimistic in the near future. The various reasons for the emergence of super bugs include irrational use of antimicrobials/antibiotics, spontaneous mutations in microbes, lack of regulatory control and supervision on antibiotic use, and lack of new antibiotics with novel mechanism of action, reluctance of industries to under research on antimicrobial resistance, frequent exposure of human to disinfectant and inappropriate choice of disinfectants. As per the WHO, British Society for antimicrobial therapy, Centre for Disease Prevention and Control (CDC), National Institute of Health, the collective underlying reasons for the existing serious antimicrobial crisis are (a) lack of new antimicrobials and antibiotics, (b) lack of diverging approach in drug discovery strategy, (c) increasing ineffectiveness of existing antibiotics, (d) increasing mutation of common pathogens, (e) irrational use of antibiotics, and (f) lack of awareness in antibiotic use [4, 5].

Furthermore, the level of drug resistance in microbes is not measurable, but on the basis of resistance levels, the drug-resistant infections can be categorized as multidrug drug-resistant (MDR), extensively drug-resistant (XDR), pan-drug-resistant (PDR) and totally drugresistant (TDR) infections [6].

Overall, the existing antibiotics used in the treatment of infectious disease since 60 years are now becoming ineffective due to drug resistance. A recent study reported that in the USA, each year at least 2 million people become infected with drug-resistant bacteria, among them 23,000 people die due to antibiotic treatment failure. In fact, the drug resistance is not a new phenomenon observed today. It has been postulated since 1940 with the discovery of penicillin and the resistance produced by Staphylococcus aureus to penicillin G (benzyl penicillin). The percentage of drug resistance in developing countries like India is 2-3-fold higher than that of developed countries like the UK and the USA [7].

\section{Types of antimicrobial resistance (AMR)}

AMR is classified into different types based on the phenomenon of drug resistance, specificity towards antibiotics and the severity of threats to human health. The phenomenon of development of resistance in microbes includes intrinsic $A M R$ (due to low permeability of cell wall to drugs), adaptive $A M R$ (environment trigger like nutrients, sub-therapeutic levels of antibiotics) and $a c$ quired AMR (resistant gene transfer from one microbe to another) [8] as shown in Fig. 1.

Based on the specificity of microbes towards antibiotics, AMR is classified as antibiotic-specific $A M R$ and antibiotic non-specific AMR. In non-specific AMR, microbes resist the entry of all small molecules into the cell, thereby preventing or decreasing the intracellular concentration of antibiotics. The mechanism of nonspecific AMR includes low cell walls permeability of drugs and downregulation or decreased porin proteins in the cell membrane (porin is one of the channel protein and is responsible for the transportation of small polar molecule and ions across the phospholipid bilayer of bacteria). In antibiotic-specific AMR, mutation or region-selective modification of specific target is responsible for drug binding (mutation of bacterial penicillin binding proteins (PBPs) to penicillin drug [9].

According to CDC 2019, the drug-resistant microbial species classified based on the severity as urgent, serious and concern threats are shown in Fig. 2 and Table 1. Urgent threats are highly magnitude AMR threats because of the noteworthy risks identified across several conditions.

These threats might not currently be widespread but have the potential to become, so a vital attention is required to limit transmission. Serious threats are due to significant antibiotic resistance; these threats will get worse and might become crucial without fragmentary public health monitoring and anticipation activities. Concerning threats are bacteria for which the risk of AMR is low and/or there are numerous therapeutic options for resistant infections. These bacterial pathogens cause severe illness [10]. 

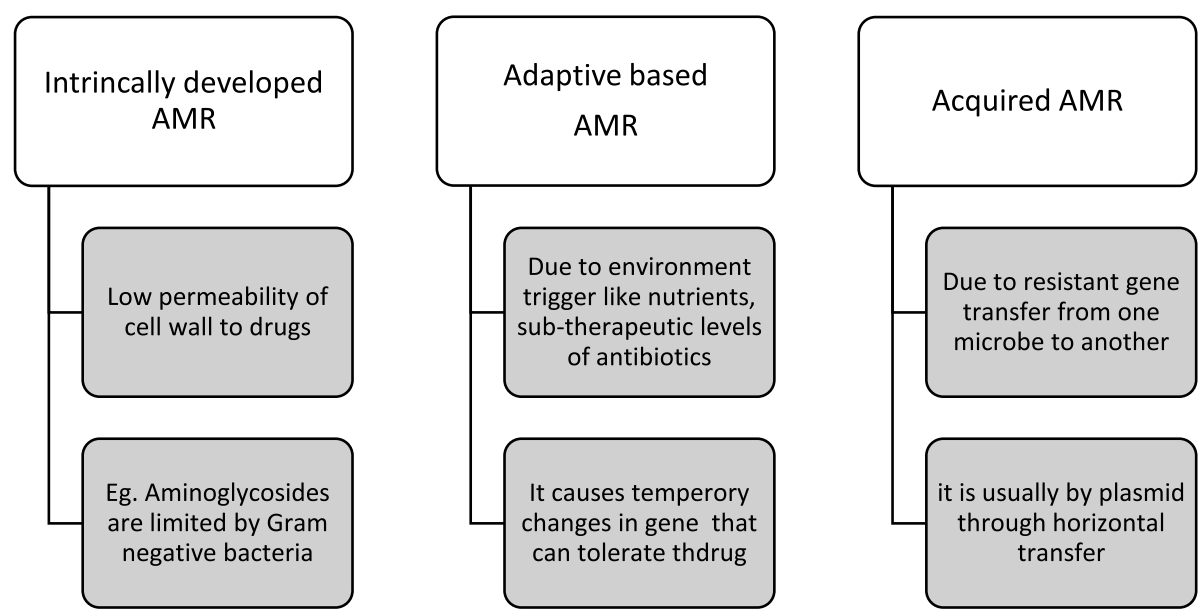

Fig. 1 Classification of drug resistance

In the early days, drug resistance was associated with antibiotic treatment, but since one decade, drug resistance has been observed with cancer chemotherapy as well. The phenomena of drug resistance by cancer cells, called as "antineoplastic resistance". In cancer drug resistance, patients will initially respond to cancer chemotherapeutics, but over time, they do not respond to chemotherapeutic agents due to the development of drug resistance by tumour cells [11] as illustrated in Fig. 3. Interestingly, the underlying mechanisms are very close to antimicrobial resistance.

\section{AMR as current global epidemics}

According to the CDC report 2019, each year about 2.8 million antibiotic-resistant infections occur in USA, resulting in about 35,000 patients died. In addition, 223,900 cases of Clostridioides difficile were also observed among which 12,800 patients died [10]. Recently, the WHO released top 10 global threats to health in 2019, among them AMR to tuberculosis drugs have accounted the huge contribution with 1.6 million deaths per year around 10 million cases [5]. The twist in the drug-resistant microbe story is that it was not the AMR

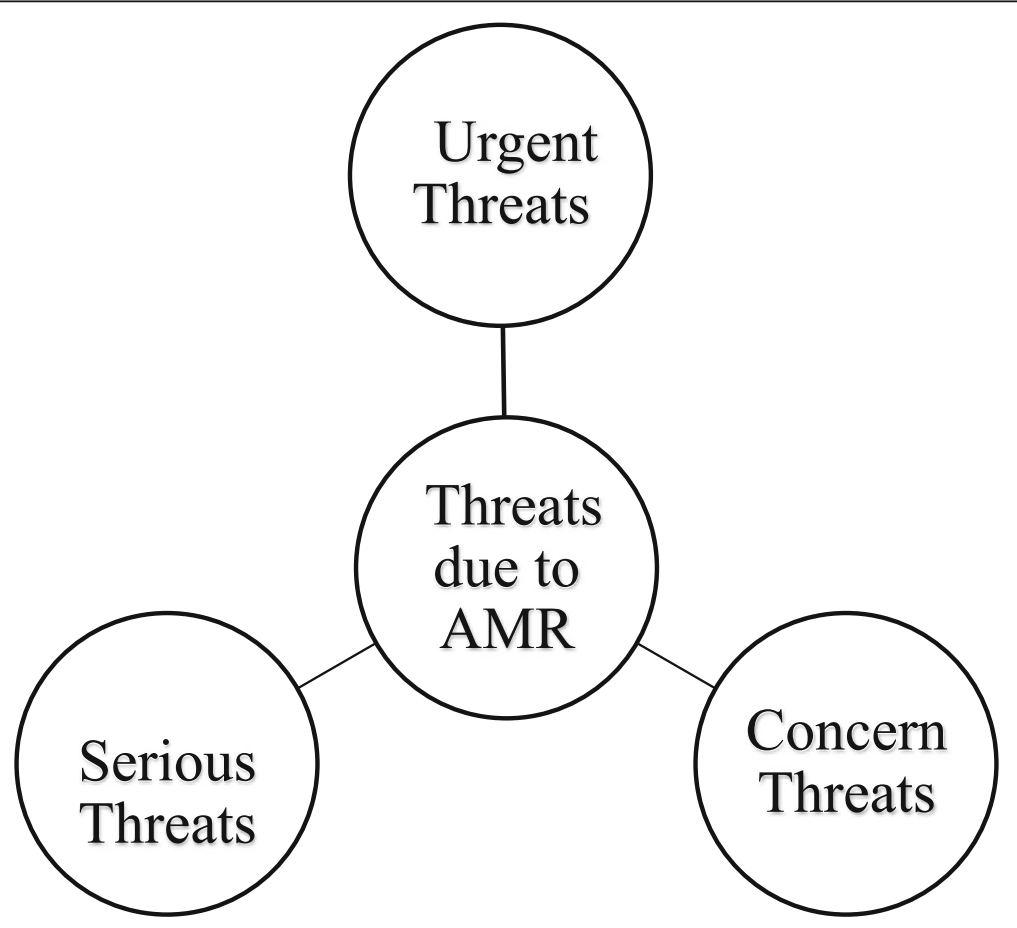

Fig. 2 CDC classification of drug resistance based on severity 
Table 1 Centre for Disease prevention and Control (CDC) classification on drug-resistant infections

\begin{tabular}{ll}
\hline Threats & Examples of drug-resistant pathogens that cause public threat \\
\hline Urgent threats & Drug-resistant Clostridium difficile, \\
& Carbapenem-resistant Enterobacteriaceae (CRE), \\
Serious threats & Drug-resistant Neisseria gonorrhoeae. \\
& Multidrug-resistant tuberculosis (MDR-TB), \\
& Drug-resistant Acinetobacter Species \\
& Drug-resistant campylobacter Species \\
& Drug-resistant Pseudomonas Species \\
& Drug-resistant Salmonellaspecies \\
& Drug-resistant Shigellaspecies \\
& Methicillin-resistant Staphylococcus aureus (MRSA) \\
& Extended spectrum $\beta$-lactamase producing Enterobacteriaceae (ESBLS), \\
& Drug-resistant Streptococcus pneumonia \\
& Fluconazole-resistant Candida albicans. \\
& Vancomycin-resistant Staphylococcus aureus (VRSA), \\
Erythromycin-resistant Group A Streptococcus & Clindamycin-resistant Group B StreptococcuS.
\end{tabular}

microbes that have spread and are found in remote areas of all the countries. In addition to the above, globally, several drug-resistant infections are in rise including the following: (a) 64\% of Staphylococcus aureus infections are notified as MRSA infections, (b) multidrug-resistant Klebsiella pneumoniae has become the most hospitalacquired infection responsible for pneumonia, bloodstream infections and infections of newborns and intensive-care unit patients, (c) recently carbapenem antibiotics have become ineffective against Klebsiella pneumoniae infections, (d) the resistance of Escherichia coli to fluoroquinolones has turned as a threat in the treatment of urinary tract infections, (e) treatment failure against gonorrhoea and its resistance to thirdgeneration cephalosporin antibiotics has been documented in countries like Australia, Austria, Canada, France, Japan, Norway, Slovenia, South Africa, Sweden and the UK of Great Britain and northern Ireland [3].

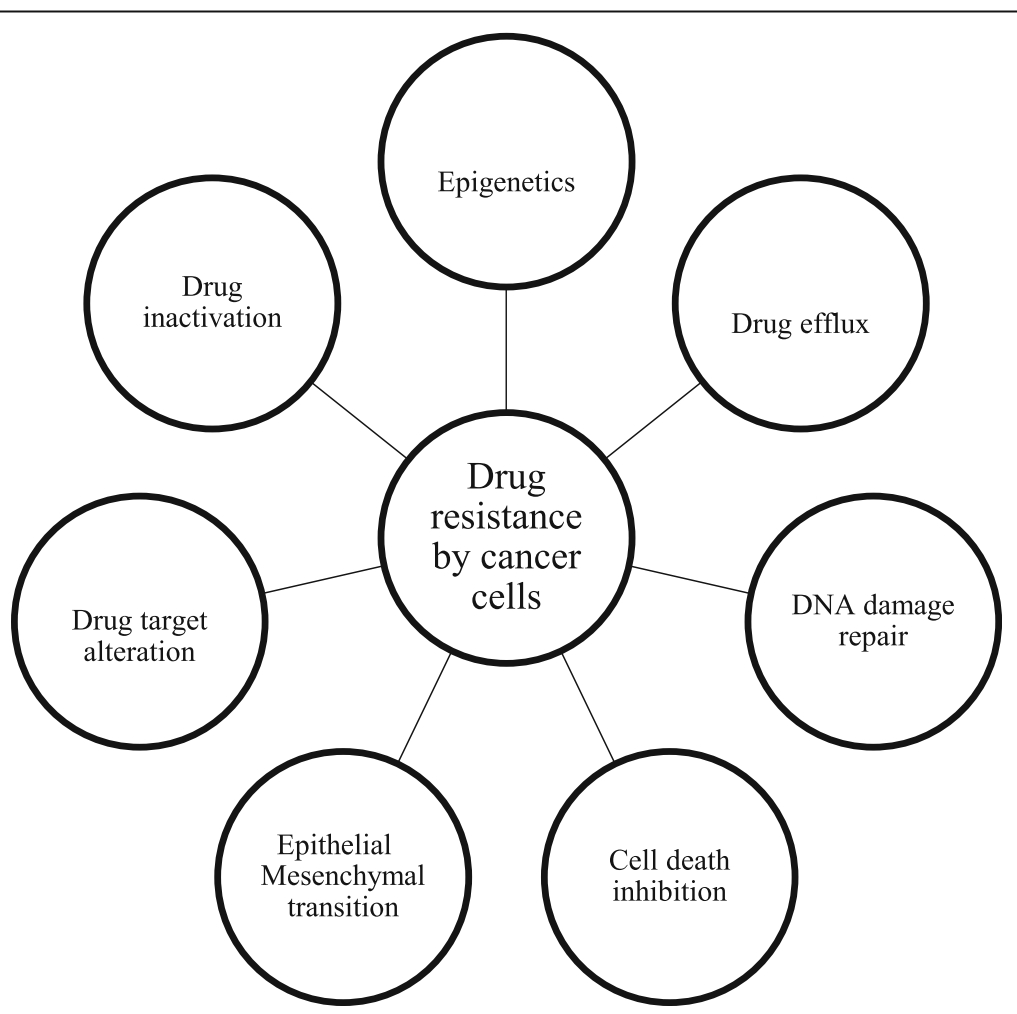

Fig. 3 Mechanism of drug resistance in cancer 
To achieve the Sustainable Development Goals, AMR needs urgent multi-sectoral action (SDGs). AMR's cost to the economy is important; prolonged disease results in longer hospital stays, the need for costlier medications and financial difficulties for those affected. The effectiveness of modern medicine in treating diseases, even during major surgery and cancer chemotherapy, would be at elevated risk without successful antimicrobials [3].

\section{Main text \\ Molecular mechanisms of drug resistance Drug-resistant bacteria}

The spreading of drug resistance is not because the entire bacterial population. Usually, this is due to one in thousands of bacteria that might have acquired a resistant gene through single or multiple de novo mutations. Bacteria develop resistance to antimicrobials through various mechanism including inactivation (by betalactamase enzyme), alteration of the target (mutation of penicillin binding protein), circumvention of the target pathway (folate synthesis) or efflux of the antimicrobials [2]. In addition, bacteria can also develop resistance through mutation in the existing genes and/or acquiring resistant genes from other strains or species [6]. The environmental reasons for the bacterial resistance are (a) severe or multiple infections in humans; (b) use of antibiotics in animals/birds which are ingested by patients; (c) incorrect antibiotics in treatment due to lack of awareness or due to inappropriate prescription and (d) inadequate serum level of antibiotics caused by in appropriate dose of antibiotics or poor pharmacokinetics or spurious antibiotics drugs or infection at the elimination phase of prior drug and one half life or patient incompliance to the recommended therapy [12]. The various drug resistance mechanisms for each class of antibiotics are enlisted in Table 2.

\section{Drug resistance in Mycobacterium tuberculosis}

The emergence of drug-resistant behaviour has been reported in the Mycobacterium tuberculosis $H_{37} R^{1}$ (mtb) strain (WHO 2016). Now, there are many clinically diagnosed drug-resistant forms of tuberculosis (DR-TB) including (1) isoniazid-resistant TB; (2) rifampicinresistant $\mathrm{TB}$; (3) totally drug-resistant tuberculosis (TDR-TB or XXDR-TB); (4) multidrug-resistant tuberculosis (MDR-TB); (5) extensively drug-resistant tuberculosis (XDR-TB); (6) mono-drug-resistant tuberculosis and (7) poly-drug-resistant tuberculosis. The abovementioned variants of TB are difficult to treat even with duration over 20 months. Despite the initiatives of TB control strategies, it seems more than $30 \%$ of the TB infections cases are beyond the incurable XDR stage. According to the WHO 2017, India has the highest incidence of TDR/MDR/XDR-TB cases (> 80\%), the TB crisis is likely to get worse and $12.4 \%$ of the patient population in India will have a variant of TB by 2025 [13]. The cost and success rate for treating drugresistant $\mathrm{TB}$ are mentioned in Table 3.

Overall, the future prediction on the treatment of drug-resistant TB epidemic is not optimistic [14]. Recently introduced new TB agents such as delamanid, bedaquiline and pretomanid demonstrated the dissatisfactory level of efficacy against drug-resistant TB and are very toxic as well $[15,16]$. Recently in the year 2020, 2-ethylthio-4-methylaminoquinazoline has been reported as inhibitor of cytochrome bc1 for TDR/MDR/XDR-TB [17]. The Mycobacterium species elicit drug resistance via both intrinsic and acquired mechanisms [15].

Intrinsic drug resistance is due to the unusual structure of mycolic acid cell wall. This unusual structure causes low permeability of antitubercular drugs through efflux mechanisms especially to tetracycline, fluoroquinolones and aminoglycosides. Mycobacterium smegmatis showed the lack of porin MspA, which accounted for 10-fold increase of lethal dose for many drugs including ampicillin, cefaloridine, vancomycin, erythromycin and rifampicin. In addition, beta-lactamase enzyme also degrades lactam antibiotics [18]. In $M$. tuberculosis, the function of gene Rv1698 is same as MspA and attributing the resistance to hydrophilic drugs. Both Rv1698 and Rv1973 are serving as a mycobacterial outer membrane protein (OMP) and they are responsible for intrinsic resistance. The physiological adaptation due to MDR determinants also accounted for intrinsic drug resistance [19].

The mycobacterial acquired resistance occurs due to the spontaneous mutations of chromosomal genes that is taking place during sub-optimal drug therapy. The responsible genes for mutations are katG, inhA, ahpC (Isoniazid), rpoB (rifampicin), pncA (Pyrazinamide), rpsL, rrs, gidB (Streptomycin), embB (Ethambutol), gyrA/gyrB (Fluoroquinolone), rrs (Kanamycin and Amikacin), tlyA (Capromycin and viomycin), ethA (Ethionamide), thyA (p-aminosalicylic acid), Rv3547 (Delamanid, PA-824 and OPC-67683) and atpE (TMC207) [20, 21]. The mechanism/role of these genes are shown in Table 4.

\section{Drug resistance in fungi}

Fungal diseases caused by diverse pathogens, including Candida, Aspergillus, Pneumocystis and Cryptococcus sp., have also developed resistance to all antifungal drugs. Among all, Candida species are ranked as the most virulent fungi and fourth most common microbes of lifethreatening bloodstream infections after bacterial 
Table 2 Reported mechanisms of drug resistance for various antibiotics

\begin{tabular}{lll}
\hline $\begin{array}{l}\text { Class of } \\
\text { antibiotics }\end{array}$ & Mechanisms & Descriptions \\
\hline $\begin{array}{ll}\text { Beta-lactam } \\
\text { antibiotics }\end{array}$ & a) Enzyme destruction & Destruction of the beta-lactam ring of antibiotic molecule. \\
$\begin{array}{l}\text { Penicillin, } \\
\text { Cephalosporin, }\end{array}$ & b) Mutation of PBPs & $\begin{array}{l}\text { Methicillin resistance is due to the modification at allosteric binding site } \\
\text { of PBPs. }\end{array}$ \\
$\begin{array}{ll}\text { Imepenam. } & \text { c) Down regulation of porins }\end{array}$ & $\begin{array}{l}\text { Diminished the transportation of polar antibiotics into the bacterial cell. } \\
\text { Pseudomonas aeruginosa, Klepsiela pneumonia resistant to imepenam }\end{array}$
\end{tabular}

Aminoglycosides a) Ribosomal mutation

Streptomycin,

Kanamycin,

Gentamycin

b) Destruction by aminoglycoside metabolizing enzyme (AME)

c) Cell membrane modification

d) Efflux pump

Fluoroquinolones a) Decreased drug update

Ciprofloxacin,

Ofloxacin,

Levofloxacin

b) Altered target

c) Qnr protein mediated

Glycopeptides Mutation in cell wall precursor component by Vancomycin replacement of C-terminal D-alanine with D-lactate or D-serine

Macrolides/ lincosamides Erythromycin, Oleondomycin

a) Target site modification by methylation (Streptococci) at 23s rRNA of $50 \mathrm{~S}$ ribosome.

b) Efflux pumps

c) Drug inactivation of enzymes

Sulphonamides Mutation of DHPS enzyme (Dihydropteroate synthase) sulfomethoxazole responsible for binding of sulphonamide.

sulfodoxine

Sulfodimidine

Tetracyclines

Doxycycline,

Minocycline,

Glycylcycline

a) Tetracycline efflux pump (efflux or TET proteins)

b) Drug modification

c) Target mutation

d) By specific ribosome protection protein (Tet $(\mathrm{O})$, a translational GTPase)
Mutation of bacterial A site on 16s RNA of 30S ribosome (Mycobacterium resistance to Streptomycin)

There are three major enzymes, AACs (AG N-N acyltransferase), ANTs (AG $\mathrm{O}$ - Nucleotidyl transferase, APHs (AG O - phosphotransferase). Among all, AACs are more common in Gram-negative bacteria.

In case of OM modification, the cell membrane is modified by incorporation of positively charged 4-amino-4-deoxy-L-arabinose, which repulses the polycationic aminoglycoside.

The efflux pump which decreases the intracellular concentration.

It may be due to the alteration in OM and activation of efflux pump. Both are common in Gram-negative bacteria, but S. aureus shows drug resistance through an efflux mechanism alone.

The two enzymes, which bind with fluoroquinolones, undergo mutation viz., DNA gyrase (Gram-negative bacteria) and topoisomerase IV (Grampositive bacteria).

Qnr protein is due to expression of mutation that protects the nucleic acid enzyme from binding to fluoroquinolones.

There are six types of resistance (Van A, Van B, Van C, Van D, Van E and $\operatorname{Van} \mathrm{G}$ ) among these $A B D E G$ are acquired resistance whereas $C$ is intrinsic. $\operatorname{Van} A$ and $B$ are located at plasmid where the rest of them located in the chromosome.

There are nearly 40 erm genes are found among them erm A, B, C, F is reported in pathogenic microbes like Streptococcus, Enterococcus and Bacteroids

In Gram-negative bacteria, it is mediated by ABC (ATP-binding cassette transporter) and MFS (major facilitator super-family). In case of Gramnegative bacteria, it is mediated by chromosomally encoded pumps.

The enzyme like esterase and phosphoesterase (Enterococci) destroys erythromycin, 14, 15 member macrolides. But these enzymes do not destroy lincosamides.

Mediated by sul 1 and sul 2 genes, which are mediated by horizontal transfer (plasmid coded). Trimethoprim shows resistance via plasmid borne resistance.

Efflux resistant genes are mediated by plasmids. Gram-positive efflux is regulated by an attenuation mechanism whereas Gram-negative efflux is mediated by repressor that binds with tetracycline.

Chemical modification tetracycline by a cytoplasmic protein in presence of NADPH and Oxygen. But still it is unclear.

Modification of 305 ribosome, which is responsible for the attachment of aminoacyl tRNA to RNA ribosome.

There are nine ribosomal protection proteins reported that protect the ribosome from tetracyclines. This is mediated by both plasmid and selftransmissible chromosomal elements (Conjugative transposons). 
Table 3 Comparative drug treatment schedule for data of TB/ MDR/XDR-TB — cost, duration and success rate

\begin{tabular}{lllll}
\hline Drug/treatment & $\begin{array}{l}\text { Drug } \\
\text { parameter }\end{array}$ & \multicolumn{3}{l}{ Drusceptible } \\
\cline { 3 - 5 } & tuberculosis & MDR-TB & XDR-TB & TDR-TB \\
\hline Isoniazid & Yes & No & No & No \\
Rifampin & Yes & No & No & No \\
Fluoroquinolones & Yes & Yes & No & No \\
Injectable & Yes & Yes & No & No \\
First line treatment & No & No & Yes & No \\
Second-line treatment & Yes & No & No & No \\
Duration of treatment & 6 months & 2 years & 2 years & $>2$ years \\
Cost of therapy & $50 \$$ & $5000 \$$ & $50,000 \$$ & $>100,000 \$$ \\
Percentage rate of cure & $90 \%$ & $50 \%$ & $10 \%$ & $0-1 \%$ \\
\hline
\end{tabular}

pathogens $[22,23]$. Thus, the mortality rate due to Candidemia is very high $(\sim 50 \%)$. Next, the Aspergillus infections are reported in hematopoietic stem cell transplant (HSCT) recipients with about $30-50 \%$ death [24]. The various mechanisms of drug resistance exerted by fungi are elucidated in Fig. 4. These mechanisms include:

Active efflux pump or transport The decreased intracellular drug concentration of antifungal agents is mediated by efflux transport systems of fungi, such as ATP-binding cassette (ABC) transporters and major facilitator super-family (MFS) transporters [25]. The genomic analysis revealed the different topologies responsible for resistance that vary from species to species. For example, Candida albicans contains 28 ABC proteins and 96 potential MFS transporters but Candida glabrata contains $18 \mathrm{ABC}$ transporters and 33 MFS transporters [26]. The upregulation of the gene
$E R G 11$ is responsible for the fluconazole resistance in C. albicans [27] whereas upregulation of Cyp51A is responsible for fluconazole-resistant Aspergillus fumigatus isolates [28].

Drug target alterations This mechanism has been notified in fungi against azoles and echinocandins. The respective target for these two drugs are a $14 \alpha-$ lanosterol demethylase and a $\beta-1,3$ glucan synthase. Among these, Lanosterol demethylase is encoded by ERG11 (C. albicans) and Cyp51A and Cyp51B (A. fumigates) [29]. The occurrence of mutations in ERG11 resulted in non-synonymous amino acid substitutions (azole-resistant C. albicans), which accounted for the decreased affinity of the target to azoles. In case of echinocandins resistance, $\beta-1$, 3glucan synthases are encoded by FKS genes [30].

Metabolic bypasses These are very common compensatory mechanisms in all microbes, where microbes divert the toxic effect of antifungal drugs. For example, fluconazole resistance in fungi is mediated through the loss-offunction mutations in the gene ERG3 which encodes a sterol $\Delta^{5,6}$ desaturase. It catalyses the introduction of a $\mathrm{C}=\mathrm{C}$ double bond in the ergosta-7,22-dienol and gives ergosterol-a final step in the biosynthesis of ergosterol [31]. In the active state, $14 \alpha$-methylated sterols (arise from azole exposure) are converted to 3,6-diol derivative. Therefore, if the fungus acquires azole resistance, it cannot produce the metabolite [32].

\section{Drug resistance in malarial parasites}

Malaria is a deadly parasitic disease occurring in humans, caused by species of Plasmodium Protozoan namely $P$. falciparum, $P$. vivax, $P$. malariae, $P$. ovale and

Table 4 Mechanism/role of mycobacterial genes responsible for resistance

\begin{tabular}{|c|c|}
\hline Genes & Mechanism/role \\
\hline KatG & Catalase/peroxidase of isoniazid \\
\hline $\operatorname{inh} A$ & Covalent attachment of INH - NAD by enoyl reductase \\
\hline ahpC & Mutation to ahpC gene causes over production of alkyl hydroperoxide reductase \\
\hline rpoB & Crucial enzyme (RNA polymerase) in the transcriptional process \\
\hline pncA & Deamidation of nicotinamide (NAM) into nicotinate \\
\hline rpsL, rrs, gidB & S12 ribosomal protein, $16 \mathrm{~S}$ rRNA, 7-methyl guanosine methyltransferase-inhibits protein synthesis \\
\hline embB & Polymerization of arabinogalactan \\
\hline gyrA, gyrB & Catalyses the ATP-dependent negative super-coiling of double-stranded closed-circular DNA \\
\hline rrs, tlyA & $16 \mathrm{~S}$ rRNA, rRNA methyltransferase-ribosome biogenesis and translation \\
\hline ethA & Catalyse the terminal reaction in the fatty acid elongation cycle \\
\hline thyA & Plays a key role in the biosynthesis of thymidylate \\
\hline Rv3547 & Activation of the drug (Delamanid) \\
\hline atpE & Encodes the $c$ part of the F0 subunit of the ATP synthase \\
\hline
\end{tabular}




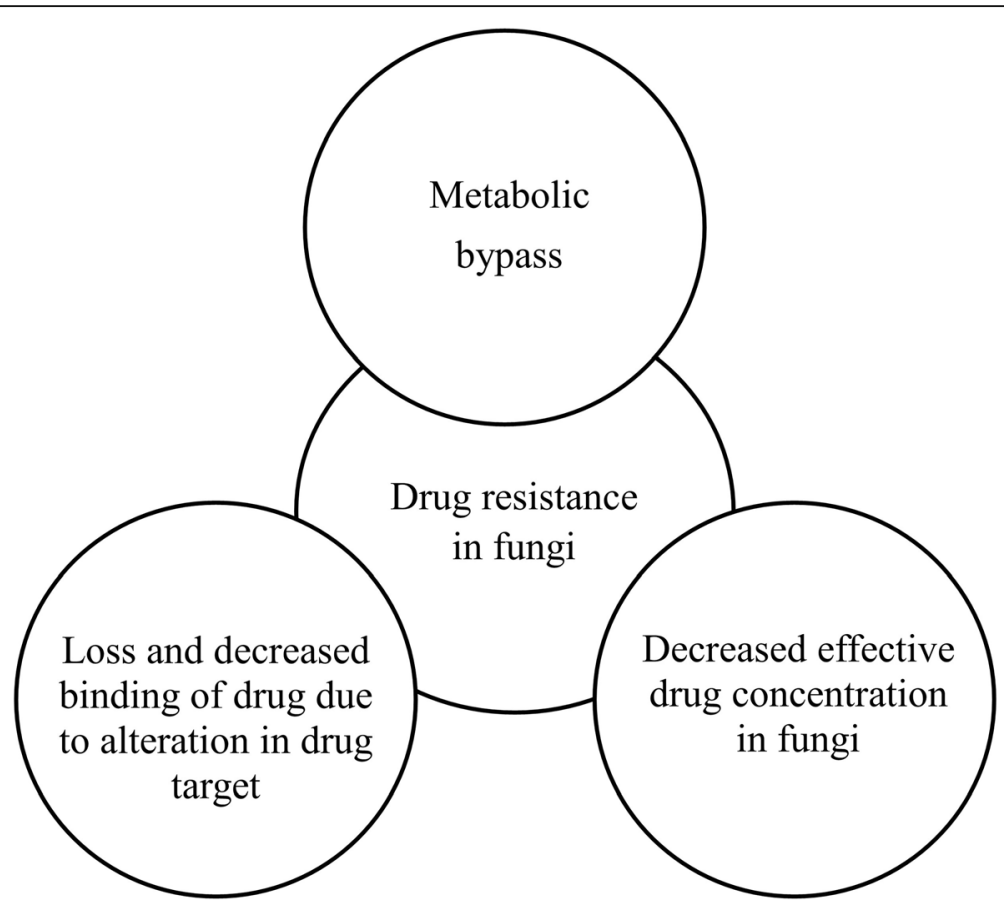

Fig. 4 Drug resistance mechanism in fungi

P. knowlesi. Among the species, Plasmodium falciparum is the most virulent parasite documented for high mortality. Every year, it kills about 2 million people, especially children. Drug resistance in malarial parasite (antimalarial drug resistance) is against all antimalarial drugs including artemisinin (artemisinin-resistant malaria) $[33,34]$. However, the de novo emergence of resistance is now treated with artemisinin combinational therapies (ACTs) with other malarial drugs [35].

The genetic basis of antimalarial drug resistance is rare, but it is spontaneous and independent of the type of antimalarial drugs. The de novo mutation of P. falciparum is single or multiple. There was a report that chloroquine-resistant P. falciparum is mutagenic, which occurred due to the mutation in a gene encoding a transporter-P. falciparum chloroquine-resistant transporter (PfCRT). Once the mutation occurs at PfCRT, the subsequent mutation occurs in the second transporter (PfMDR1) and this is responsible for the modulation of the level of resistance. Nevertheless, the significant role of PfMDR1 mutation in therapeutic response of chloroquine treatment is unknown $[35,36]$.

Another gene Pfnhe1 found in P. falciparum, coded for sodium hydrogen exchanger $\left(\mathrm{Na}^{+} / \mathrm{H}^{+}\right.$exchanger or PfNHE), is associated with quinine resistance. The bifunctional dihydrofolate reductase-thymidylate synthase from P. falciparum (PfDHFR-TS) located on chromosome 4 for pfDHFR responsible for pyrimethamine resistance. Cytochrome b (Cytb) gene is a subunit of cytochrome bc1 complex is responsible for binding of atovaquone at ubiquinol site. The mutation of this gene is responsible for atovaquone resistance. Artemisinin resistance is due to the single-nucleotide polymorphisms; Plasmodium's K13 gene accounted for unfolded protein response pathway. This antagonizes the pro-oxidant activity of artemisinin in parasites $[37,38]$. The WHO already banned the oral artemisinin-based monotherapy (oAMT) which develops and spreads the drug resistance to artemisinins [39].

\section{Drug resistance in virus}

The viral replication biology is very critical not only for understanding the evolution of virus towards drug resistance, but also for developing new antiviral drugs. The drug resistance in virus has been well documented including for hepatitis $\mathrm{C}$, influenza A virus (IAV), herpes simplex virus (HSV), human cytomegalovirus (HCMV), retrovirus HIV and hepatitis B virus (HBV) [40].

Hepatitis $\mathrm{C}$ virus (HCV) is well known for its mutation rate and high genomic diversity and is facilitated by its frequent replication and very low proofreading function of viral encoded RNA polymerase. The direct-acting antiviral drug (DAA) usually inhibits either protease or polymerase activity. The drug which inhibits protease possess low genetic barrier to resistance, it means that resistance develops very easily through one or few mutations. To overcome this HCV resistance, the combinations of the DAA agents (ledipasvir and sofosbuvir) are 
recommended and these combinations exhibit higher genetic barrier to resistance with very less crossresistance between the two drugs [41].

IAV is found with small genome codes with 11 proteins including its two surface antigen proteins namely hemagglutinin (HA) and neuraminidase (NA). These surface antigens, HA and NA, evolve relatively more rapid and higher than any other viral proteins. The current drugs used to treat IAV infections are NA inhibitors and they inhibit the detachment of viral envelope from the cell membrane. The most popular NA inhibitor oseltamivir has found to be associated with the mutation of H274Y and confers the high level of resistance. The drug zanamivir has not been observed to develop resistance, but is not recommended for frequent administration, this may also have contributed to the rarity of resistance. The latest antiviral drug called favipiravir acts by inducing mutagenesis in the IAV and the level of resistance to favipiravir is yet to be documented [42].

HSV contains a large genome with low diversity as compared with RNA viruses. Usually, the systemic antiviral therapy is needed only in immune-compromised patients. The common drugs are acyclovir and its derivatives and all nucleoside inhibitors. For these agents, resistance mutations are well known, they affect either thymidine kinase or DNA polymerase [43].

The genome of HCMV is diverse within-host and exhibits different levels of polymorphism when compared to RNA viruses, even though DNA polymerase possesses a higher rate of fidelity than RNA virus polymerases [44]. The treatment for HCMV infections usually involves the use of nucleoside analogues such as ganciclovir and cidofovir. Resistance develops either in a viral kinase responsible for phosphorylation or in the DNA polymerase [44].

HIV is a retrovirus encoding an RNA genome within the virion, but it replicates its genome using reverse transcriptase and generates a copy of DNA and eventually double-stranded DNA. During the drug treatment, the viral reverse transcriptase is relatively more prone to error and shows a high rate of nucleotide substitutions, increased population diversity and frequent resistance mutations. The HIV therapy today is a multiple drug regimen consisting of nucleoside reverse-transcriptase inhibitors, non-nucleoside reverse-transcriptase inhibitors, protease inhibitors and/or integrase inhibitors [45].

HBV is an enveloped DNA virus, and it transcript to RNA intermediate and then again reverse transcribed to DNA; furthermore, the HBV exists as a quasi-species with high levels of diversity through very poor proofreading during reverse transcription phase. Therefore, like RNA viruses, HBV infections preserve polymorphism at all nucleotide positions within a host, thus providing the way for resistance mutations to fight against drugs. HBV is commonly treated with reversetranscriptase inhibitors, particularly lamivudine [46].

\section{Drug resistance in tumour cells}

In the early days, drug resistance was associated with antibiotic treatment, but since one decade, drug resistance has been observed with cancer chemotherapy as well. The phenomena of drug resistance by cancer cells is called "antineoplastic resistance". In cancer drug resistance, patients will initially respond to cancer chemotherapeutics, but over time, they do not respond to chemotherapeutic agents due to the development of drug resistance by tumour cells [11] as illustrated in Fig. 3. Interestingly, the underlying mechanisms are very close to antimicrobial resistance.

The distinct feature of resistance is usually a tumour cell survives and relapses during and after chemotherapy by a variety of intracellular mechanisms acquired by mutations. Various intracellular mechanisms exerted by resistant tumour cell are altered drug metabolism (increased drug efflux, decreased drug intake, enhanced drug detoxification, sequestration), modification of a drug target, dysregulation of apoptotic protein and enhanced DNA repair [37]. This antineoplastic resistance occurs due to DNA mutations of tumour cells, and they are (a) DNA-synthesis gene over expression (against anti-metabolite drugs); (b) altered target molecules (against tyrosine kinase antagonists); (c) enzyme deactivation; (d) altered membrane transport; (e) enhanced DNA repair-ERCC1 (against platinum-based drugs); (f) resistance to drug-induced cell cycle arrest and (g) resistance to apoptosis [38]. The above mechanisms are shown in Fig. 5.

\section{Recent development in drug discovery against drug resistance}

Policies on discovery of new drugs against drug resistance

Developed countries have already accelerated the discovery of new sterile antibiotic molecules for the treatment drug-resistant infectious diseases including MDR/XDR-TB. The reflected recommendations are (a) to support more basic research relevant to antimicrobial drug development; (b) to support the study of virulence factors, host-pathogen interactions and genome mining; (c) to discover newer agents with new mechanisms of action and (d) to exploit the new natural and biotechnological products in antimicrobial drug discovery $[3,4]$.

As a result, there were many new antibiotic molecules developed, but were precluded from further development due to various reasons including the following: (1) the newer antibiotics are structurally similar to existing ones, so resistance is not restricted; (2) all targets were 


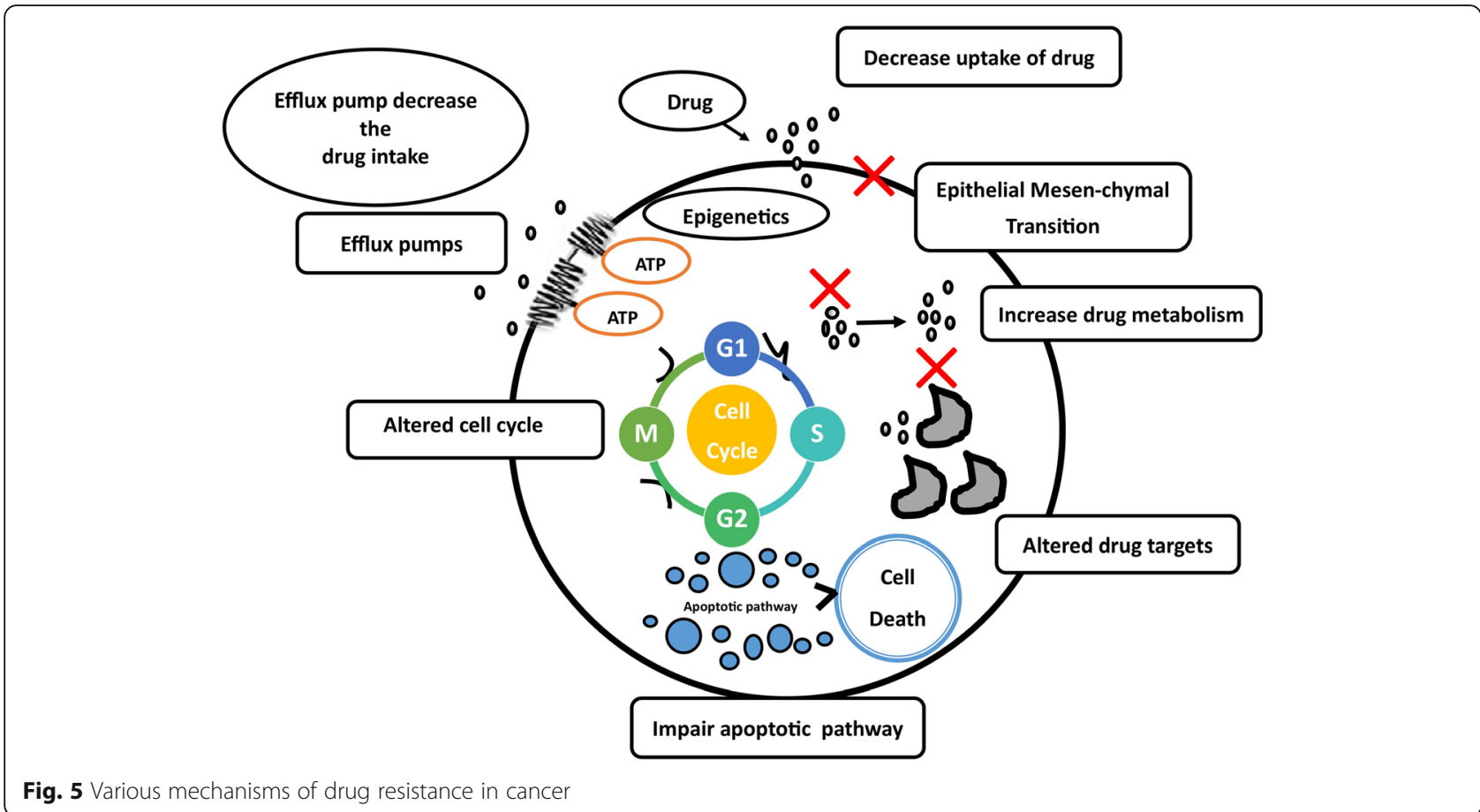

Fig. 5 Various mechanisms of drug resistance in cancer

highly susceptible for mutations (MurA, PBP2); (3) spontaneous resistant mechanisms of microbes are not predictable; (4) genome variation in targets from strain to strain; (5) cytotoxicity; (6) carcinogenicity; (7) nonselectivity of highly potent molecules; (8) poor drugable property. As per the existing reports, more than $90 \%$ of the developed hit molecules were declared as not suitable for drug-resistant infections, whilst the rest of them were low potent against super bugs or have high cytotoxicity in humans (including Oritavancin and Dalvance). Therefore, the WHO declared this era as the antibiotic crisis era, it means there is an urgent need for new agents and new strategy to save millions of lives from antimicrobial resistance $[5,7]$.

\section{Drug discovery void}

With the review of the time scale of the discovery of new antibiotics, drug resistance was observed with the discovery of penicillin itself. The discovery of betalactamase inhibitors such as clavulanic acid and sulbactam is an outcome of research to fight against drug resistance. After the introduction methicillin in antimicrobial therapy in 1960, the emerging scope of drugresistant incidents was significantly high. On the other hand, there is a void in new drug discovery for infections since 1990 till date. Though centrolineal approach was introduced in 2010, the mechanism was not a new one [2]. A timeline of various antibiotics introduced in the market is shown in Fig. 6. This void may be due to negligence on antimicrobial research or due to stringent regulatory guidelines on toxicity including tripartite $\mathrm{ICH}$ and OECD guidelines.

\section{Essentiality of gene paradox}

In the optimization of lead compound against drug resistance, the selected drug target or microbial protein should necessarily be valid and reliable in the resistant genome. Here, there is a challenge, despite the gene dispensability in resistant microbes or tumour cell and the possible potential targets; there is always a considerable amount of gene encoded proteins responsible for the unknown metabolic function. Hence, the full function of gene needs to be addressed in the validation process of a drug target. In practicality, it is not that so easy to build or define a chemical-based screening assay for the selected protein of unknown function [47, 48]. For example, 303 genes (7\% of the E. coli genome) are found to be responsible for its growth in media (typical Waksman-screen conditions). Nevertheless, the nutrient deprivation and chemical perturbation have shown that further 258 genes are conditionally essential [49]. Thus, these 258 gene encoded enzymes are important for survival and its drug-resistant mechanism. Unfortunately, these types of investigations are ignored in the antibacterial drug discovery [50]. Still considerable efforts were made to reveal essential genes of model microorganisms 


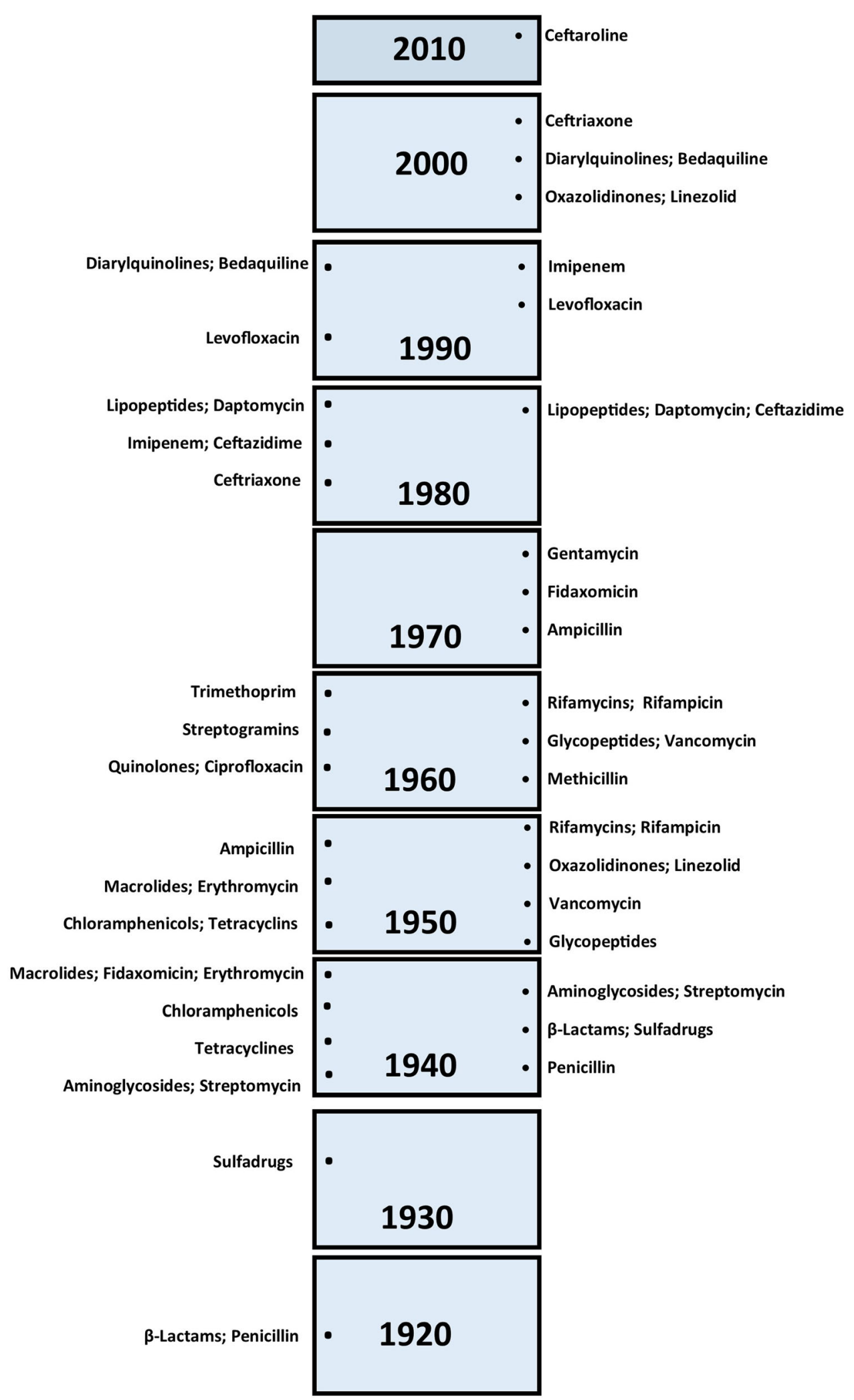

Fig. 6 Timeline of various antibiotics discovery (left) and resistance observed (right) 
through in vitro techniques; however, the essential genes responsible for the viability of resistant pathogens in infectious condition are only little understood [51].

\section{Random transposon mutagenesis approach}

Transposon mutagenesis known as transposition mutagenesis, it allows a gene to be transferred into the host organism's chromosome that interrupts or modifies the function of an existing gene on the chromosome and cause mutation. This transposon-based mutagenesis is a powerful method to identify genetic elements that control specific phenotypes in antibacterial resistance. Essential genes can be assessed in drug-resistant pathogens using a random transposon mutagenesis approach [52]. This approach can assess a larger pool of mutants, which can be enabled by parallel DNA sequencing. This application was done for investigating the genomic requirements of $P$. aeruginosa in a sputum sample of patient with cystic fibrosis [53].

\section{Interfering in vitamin biosynthesis of pathogens}

Vitamin biosynthesis is a well-known process essential for survival of all pathogens, especially bacteria and fungi. The in vivo essential genes can represent the emerging targets, which are still unexplored in the current antibacterial and antifungal drug discovery [54]. For example, vitamin B2 (riboflavin) acts as a cofactor for ornithine- $\mathrm{N}^{5}$-monooxygenase SidA in $A s$ pergillus fumigates by catalysing the first step in the biosynthesis of siderophores. Siderophores are known virulence factors which allow the fungi to overcome the iron deficiency [55]. Thus, the inhibition of riboflavin biosynthetic pathway in fungi reduces the formation of siderophores, which will inhibit the fungal iron acquisition and growth during infection. The combination of sulfamethoxazole and trimethoprim inhibit two key vitamin B9/folate biosynthetic enzymes of Pneumocystis jirovecii [56].

\section{Drug screening in a non-conventional growth media}

For the first time, this in vitro approach was employed for targeting the glyoxylate shunt of $P$. aeruginosa in pulmonary infection. This screening prioritizes the active compounds in nutrient-limited media where the media contains only acetate as a source of carbon. This screening procedure also prioritizes the inactive compounds only when glucose alone used as source. Supplementation of nutrientlimited media has proven to be a challenging mechanistic methodology to understand metabolic pathways and to investigate the mechanism of action of potent molecules [57]. Soon after the prioritization of the antibacterial lead, which was active in the absence of nutrient supplements, the systematic supplementation of individual and pools of metabolites to media is done to elucidate the mechanisms of action. There are reports on identified lead compounds which can target glycine, folate and biotin synthesis in E. coli [58].

\section{Targeting the quorum-sensing virulence pathway}

Quorum sensing is defined as the process of regulating the gene expression as a response to the change in cell population. It is very common in bacteria where the quorum-sensing bacteria release characteristic chemical signal molecules (auto inducers). The concentrations of auto inducers are directly proportional to the density of cell population. This approach was done on $P$. aeruginosa and has produced promising lead compounds. The resultant compounds were tested in animal models of induced infection without disturbing the in vitro growth [59].

\section{Use of host model of disease}

The macrophages are infected with M. tuberculosis and then the infected macrophages can identify the lead compounds. Usually, chemical compounds which interfere in respiratory mechanism like inhibitors of cytochrome bc1 complex may be discovered using this host model disease [60].

\section{Genomic-chemical network}

The existing drug discovery strategies have witnessed the transformation in the interpretation of the cell function based on genome. In yeast and bacteria, the investigation of interaction among genes and proteins has already established as a network of functional interactions. The classic mapping between cell metabolism and cell signalling are now displaced by cell network model. The cell network model characterizes a well-connected web of proteins and genes that are responsible for the complexity and redundancy [61]. This network helps in the study of synthetic lethality in the model organism to reveal the density of gene interactions and could serve as space for designing new drugs or combinations of drugs that probably inhibit the interacting gene. Indeed, this is a compelling case for a combinatorial approach, molecular docking and pharmacophore modelling to discover new antibiotics. There are reports available where the antibiotic sensitivity profile determined the $E$. coli gene knockout collection [62]. The overall importance of gene expression profiling in new drug discovery is represented in Fig. 7.

\section{Synthetic viability and drug targets}

For example, the synthetic viability is found in the biosynthetic pathway of the wall teichoic acid (WTA) of 


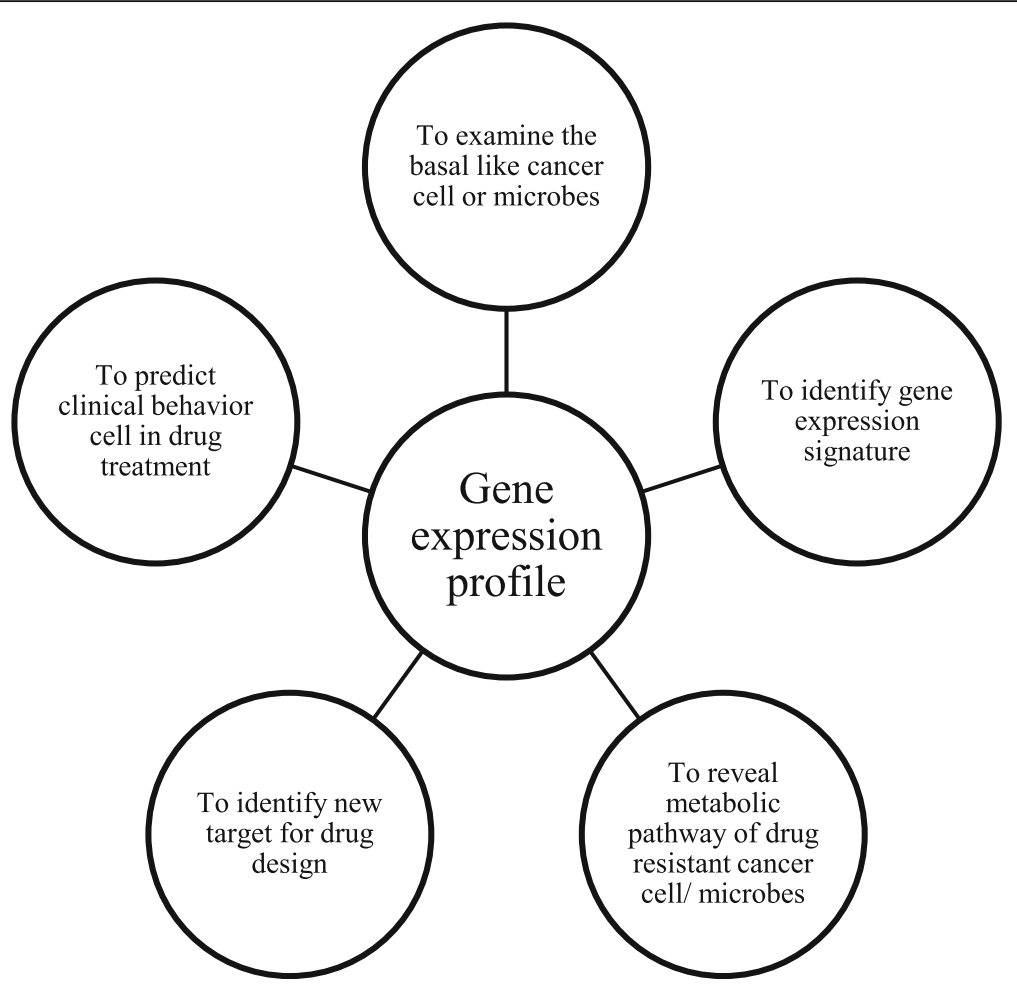

Fig. 7 Importance of gene expression profiling in drug discovery against drug resistance

Gram-positive bacteria. The early steps in the biosynthetic pathway are dispensable, but the genes responsible for late-step enzymes are an essential phenotype. The essential phenotypes of the late genes are found to be due in the accumulation of biosynthetic intermediates of WTA and are linked to undecaprenyl moiety [61]. This undecaprenyl phosphate is acting as a lipid carrier in the process of peptidoglycan wall assembly. Thus, a unique dispensability pattern of WTA genes can serve as a basis for the discovery of new lead compounds [63].

\section{Antibiotic adjuvants and combinatorial discovery}

The antibiotic drugs possess dense and complex chemical-gene interaction network that resist perturbation. These networks provide a space for new targets for the design of antibiotic adjuvants. The antibiotic adjuvant is a non-antibiotic molecule that enhances the antimicrobial activity of antibiotics or it reduces the microbial resistance during treatment. The antimicrobial adjuvants have two major advantages in drug resistance viz increase the effectiveness of antimicrobials and reduce the occurrence of mutations. But this emerging complex network interaction of bacterial cell is quite challenging one for the modern genes-to-drugs approach and its ideology of targetvalidation measure [64]. The chemical-genomic characterization shall disclose the information and predictions about the pathogens mechanism of drug resistance. So if any lead compound discovered and characterized in this approach, it could be a ready probe for target validation and understanding of the network of the target. The suppressors are more commonly employed in drug-resistant tumours.

Previously, the combinations of antibiotic administration, such as trimethoprim plus sulfamethoxazole and amoxicillin plus $\beta$-lactamase inhibitor (Clavulanic acid), have been demonstrated as an effective strategy in the management of drug resistance. Even today, clinicians combine two classes of antibiotics such as $\beta$-lactams and aminoglycosides for achieving synergism if pathogens are unknown or to suppress the surfacing of drug resistance. Thus, the discovery of adjuvant combinations of two molecules would be more beneficial to reduce the incidence of resistance $[3,5]$.

Example, antibiotic efficacy of Novobiocin in E. coli was augmented by four new compounds that affect cell shape and membrane permeability [65]. Another example, aspergillomarasmine A (notorious carbapenemase NDM-1 blockers), reversed the carbapenem resistance in Gram-negative pathogens and K. pneumonia-infected mouse model. It was reported that loperamide induces 
destabilization of membrane potential in bacteria, which facilitates the increased permeability of minocycline, especially in Gram-negative bacteria [66]. In the same way, ticlopidine increases the efficacy of $\beta$-lactam antibiotics against MRSA through inhibition of the synthesis of WTA.

However, the combination approach can be consistent with the increased understanding of successful antibiotics mechanism if they bind with multiple numbers of targets [67]. Nevertheless, the modern target-based discovery approach devastatingly strives to identify the reliable target selectivity with minimized toxicity. Thus, the adjuvant approach adds an advantage to reuse the old and exhausted antibiotics in drug resistance era. But, the cause of unexpected drug-drug interactions must also be considered [68].

\section{Chemical space vs. biological space}

To achieve the validated target in drug-resistant era, the gap between the compound library (more than $10^{20}$ ) and biological space $\left(10^{5}\right)$ is enormous as shown in Fig. 8 . Thus, combination of computational, experimental screening and cellular genomic networks need to be employed for validating the drug target.

These combinations may provide different fundamental techniques of modelling of biological proteins in the living cell system; it enables the researchers to find out effective drug strategies to solve the varying problems of AMR. These techniques also help in the analysis and interpretation of data like sequence of amino acid residues in proteins and interactions of protein ligand at the molecular level. Next challenge is that the integrative response between chemical structure and biology is not completely explored. Furthermore, the integrative response differs among different class of chemical compounds one from each other, despite the mechanism or drug target is similar or dissimilar. For example, modification of metronidazole at $\mathrm{N}^{1}$ and $\mathrm{C}^{2}$ positions improves the $\mathrm{EC}_{50}$ (against Giardia lamblia) to $39 \mathrm{nM}$ from 2630 nM [67] shown in Fig. 9.

Although substantial development in the establishment of microbial genome has been taking place in recent time, yet the satisfactory outcome on cell biology of resistant microbes has to be much explored [69]. Thus, for future-generation antibiotics, the integrated knowledge among environmental response of microbes, growth regulation in mutants and signal transductions are needed to be explored, as represented in Fig. 10.

\section{Identification of target by transcriptome profiling}

In the field of molecular biology, gene expression profiling is the measurement of activity of thousands of genes (expression) at once, which is responsible for cellular function. The gene expression profiling is not new but more commonly used to differentiate normal cell from abnormal cell (tumour cell) or one type of cell from another with respect to (a) cell division; (b) response of cell to the environment and (c) response of cell to drug treatment.

In case of antimicrobial resistance, although several mutations in a pathogen are responsible for drug resistance, the relationships between mutations and phenotypic changes that are responsible for drug resistance not much explored. Also, it is noted that single mutation may cause many phenotype changes in organisms; thus, mutation-induced phenotype changes can cause both drug susceptibility and drug resistances [70].

The molecular mechanism of many drug-resistant microbes, parasites and cancer (especially breast cancer) with reference to biological or clinical behaviour is not well explored. In this, the microarray gene expression profiling would benefit us in many ways to find a solution as shown in the Fig. 7. The transcriptome profiling of antimicrobial resistance of Pseudomonas aeruginosa to fluoroquinolones and beta-lactam antibiotics was well established. Usually, the transcriptome profiling adapts the qualitative RNA sequencing to identify the genetic determinants [71]. It is believed that it can be better for nextgeneration sequencing (NGS). The NGS can accomplish (a) pathogen identification, (b) prompt initiation of target individualized treatment and (c) implementation of optimized control of drug resistance.

\section{New antimicrobial molecules against drug resistance}

The various drug discovery approaches have transformed drastically since 1925 (Table 5). The various approaches in drug discovery strategies are listed in Table 5. Newly identified molecules with novel mechanism of action in microbes are enlisted in Table 6. Subsequently the list of natural molecules with MIC values is reported in Table 7.

\section{Photosensitization}

There are three stages in killing pathogen by photosensitization. First, the photosensitization of drug-resistant pathogen is rationally potentiated with combination of visible light and using of inorganic salts (potassium iodide). Secondly, the use of blue and violet light is done to activate the photoactive porphyrins in bacteria. Lastly, the safe UV rays at a wavelength range from 200 to 230 $\mathrm{nm}$ are used to kill microbial cells without damaging host mammalian cells. The evidence from in vitro studies has been established that the photosensitization can kill multidrug-resistant bacteria and they do not develop any resistance to UV light. Hence, there are animal 


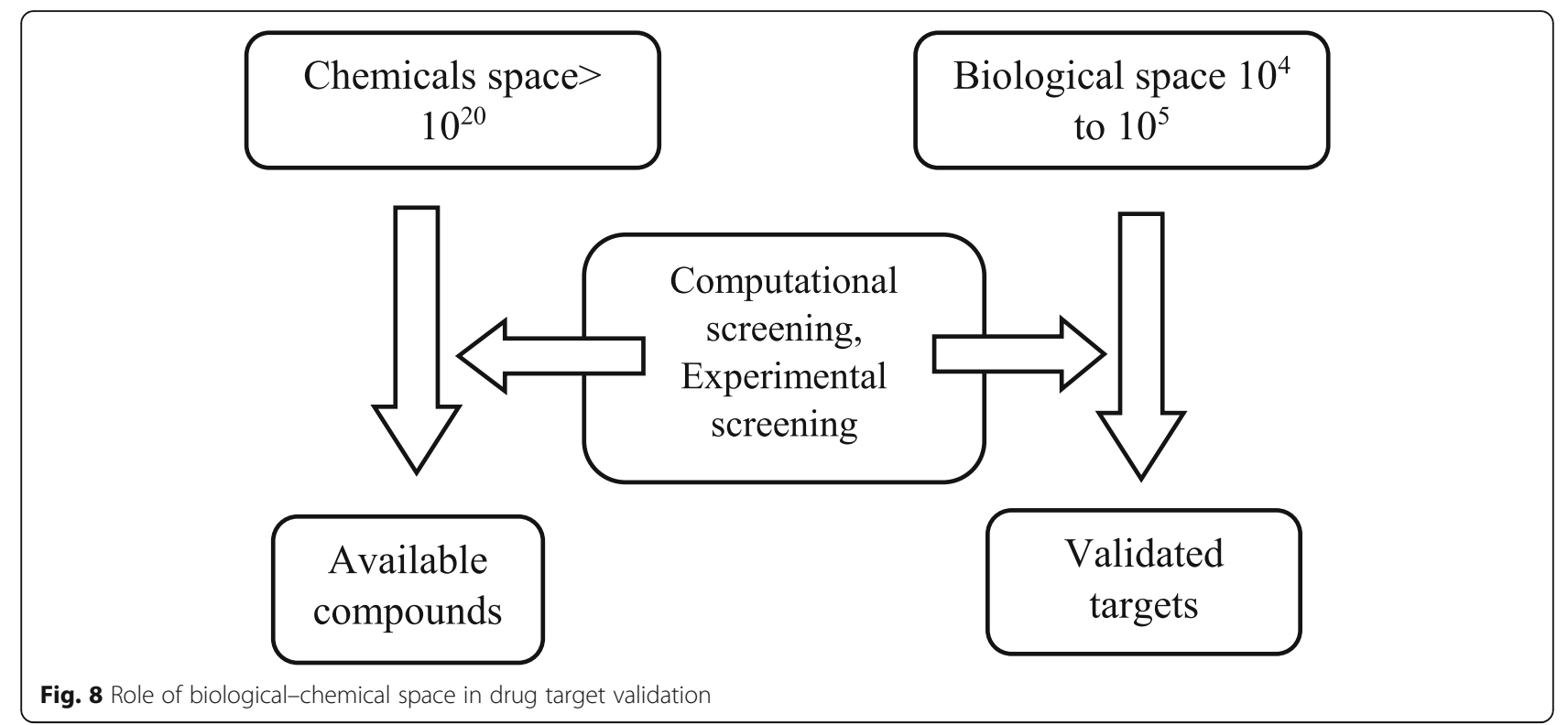

models for localized infections caused by resistant species that are monitored by non-invasive bioluminescence imaging (BLI). Bioluminescence imaging (BLI) is a technique that reports activity at the molecular level using light produced by enzyme-catalysed reactions. For non-invasive imaging in cell biology and small animal studies, bioluminescent reporters need a small chemical substrate. Incident light such as fluorescence or phosphorescence is not necessary for BLI, preventing photo toxicity [72]. The disadvantages of photosensitivity are (a) photosensitization after treatment, (b) the efficacy of the tumour treatment influenced by the precise delivery of the light, (c) oxygenation of tissue is vital by the photodynamic effect, (d) current photosensitivity methods are not expedient to treat metastatic cancers [73].

\section{Antimicrobial or host defence peptide}

Antimicrobial peptides (AMPs) are also known as host defence peptides (HDPs). These peptides are found in all living beings as a part of innate immune response. The exploration of the differences exists between prokaryotic and eukaryotic cells with respect to HDPs and may provide the idea for targeting the antimicrobial peptides. Peptide-based antibiotics are relatively small molecules, and unlike classical antibiotics, they act very fast and are broad spectrum; thus, they are lethal to several types of pathogens. Further, interestingly, they seem to be free from several drug resistance mechanisms of microbes. The distinct advantage of peptides over classical antibiotics is they portray a highly modular synthetic antimicrobial system and they kill microbes by destroying their membrane. In addition to antibiotics activity, these

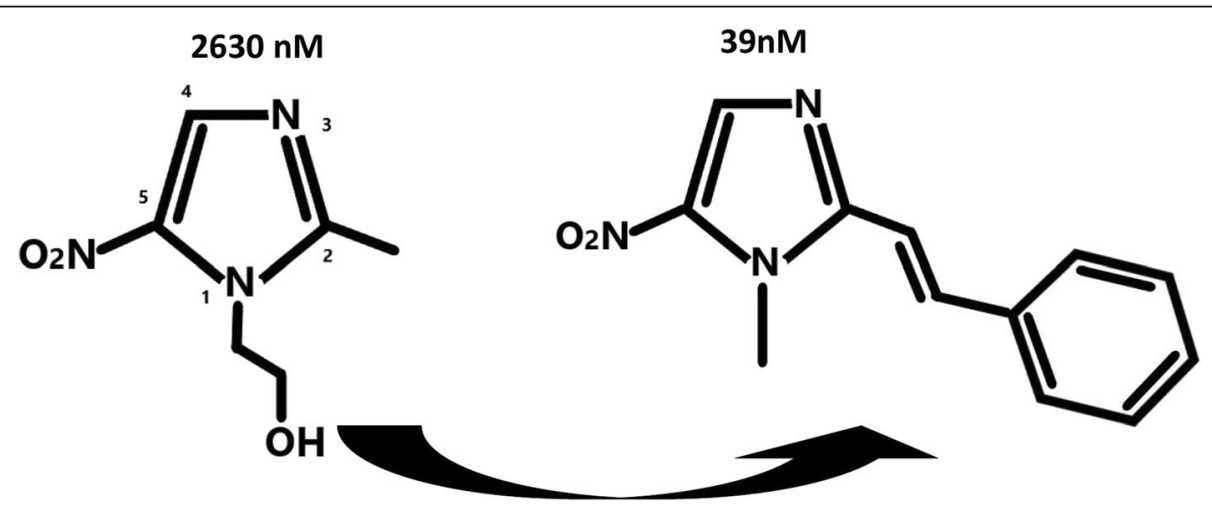

Fig. 9 Example of structural diversity in potency —-metronidazole and its potent derivative 


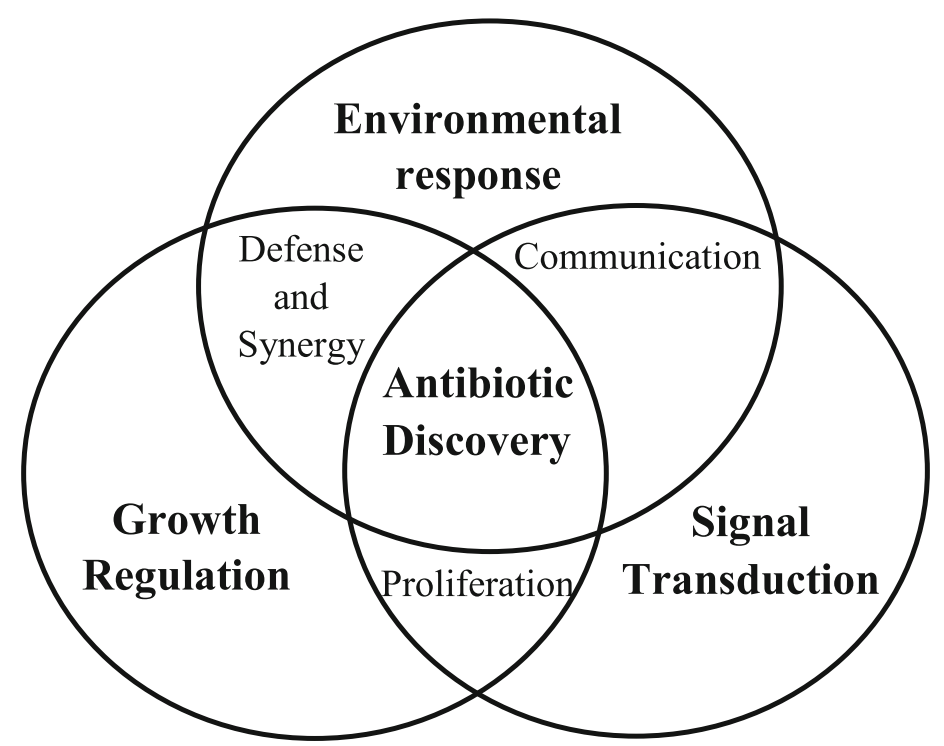

Fig. 10 Strategies need for future antibiotic discovery

peptides can also inhibit enveloped viruses, fungi and cancerous cells [74]. These peptides are also acting as immunomodulators (examples of AMPs are dermicidin (cationic human peptide), cecropins, andropin, moricin, ceratotoxin, melittin (cationic alpha-helical insect peptide), magainin, dermaseptin, bombinin, brevinin-1, esculentins and buforin II (amphibians), indolicidin (cattle) and defensins (anionic human peptide)). The AMP drugs approved by FDA are bacitracin, dalbavancin, daptomycin, enfuvirtide, oritavancin, teicoplanin, telaprevir, telavancin, vancomycin, etc. [75]. Nearly 36 AMPs are in clinical trials (clinical/preclinical), among these MU1140, D2A21, HB1275, HB1345, arenicin, AP114, AP138, novamycin, novarifyn, avidocin and purocin were in preclinical stage; NVB-302 and friulimicin B were in phase I studies; EA-230, CZEN-002, delmitide, ghrelin, hLF1-11,
Wap-8294A2, C16G2, DPK-060, PAC113, LTX-109, OP-145, LL-37 and novexatin were in phase II studies; and D2A21, XMP-629, neuprex, delmitide, ghrelin, SGX942, PXL01, POL7080, p2TA, iseganan, pexiganan, omiganan, surotomycin and ramoplanin were in phase III [76].

\section{Antievolution drugs}

Despite the mechanisms of antibiotic-induced mutagenesis in microbes, the need of understanding the underlying molecular mechanism of evolutionary resistance in pathogenic bacteria against our immune systems and antibiotics is very essential. Recently, in 2019, John et al. found that ciprofloxacin induced the mutation via reactive oxygen species (ROS) in E. coli. The ROS can enhance the stress environment by triggering the

Table 5 Various timeline dependant drug discovery approaches and the expected success rate

\begin{tabular}{llll}
\hline Era & Year(s) & Approach & Success rate \\
\hline Golden era & $1950 \mathrm{~s}$ & Natural product research & Hhole cell screening \\
Medicinal chemistry era & & Synthetic tweaking & Whole cell screening \\
& $1975 \mathrm{~s}$ & Broad spectrum & High \\
Resistant era & & Modern drug discovery \\
& $2000 \mathrm{~s}$ & Target based & Ligand based \\
& & Broad spectrum & Low \\
Narrow-spectrum era & $2025 \mathrm{~s}$ & Unconventional discovery & In vivo essential target \\
& & Combinatorial approach \\
& & Diagnostic development & Predicted \\
\hline
\end{tabular}


Table 6 Newly identified potent molecules against drug-resistant infection with their reported mechanisms

\begin{tabular}{l}
\hline Name of the drug \\
Chemical structure
\end{tabular}

Contezolid

(Antimicrobial)<smiles>O=C1C=CN(c2c(F)cc(N3C[C@H](CNc4ccon4)OC3=O)c(F)c2F)CC1</smiles>

Protein synthesis inhibition by binding to the $\mathrm{V}$ region of $23 \mathrm{~S}$ rRNA
Macozinone (Antitubercular)<smiles>O=c1nc(N2CCN(CC3CCCCC3)CC2)sc2c([N+](=O)[O-])cc(C(F)(F)F)cc12</smiles>

Daquiline (Antitubercular)<smiles>COc1nc2ccc(Br)cc2cc1[C@@H](c1ccccc1)[C@@](O)(CCN(C)C)c1cccc2ccccc12</smiles>

Spectinamide 1810 (MDR-TB)

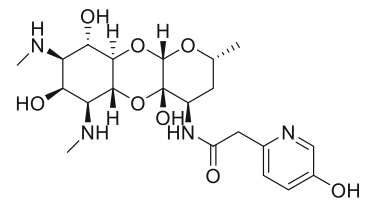

Nitazoxanide (Antiprotozoal drug used in Pulmonary tuberculosis<smiles>CC(=O)Oc1ccccc1C(=O)Nc1ncc([N+](=O)[O-])s1</smiles>

Delamanid (Nitro-dihydroimidazooxazole) (MDR-TB)

(Prodrug)<smiles>COc1nc2ccc(Br)cc2cc1[C@@H](c1ccccc1)[C@@](O)(CCN(C)C)c1cccc2ccccc12</smiles>

Azaindole (Antitubercular)<smiles>COc1ncnc(Cn2cc(C(=O)NCCO)c3ncc(C)cc32)c1C</smiles>

Cell Wall: DprE1. It also inhibits PDE6 with an $\mathrm{IC}_{50}$ value of $4 \mu \mathrm{M}$

PBTZ169 covalently inhibit DprE1, an enzyme essential for the biosynthesis of key cell wall components.

Targeting the adenosin triphosphate (ATP) synthase enzyme of the TB mycobacteria. ATP-synthase is used in the process by which M.tb generates its energy supply.

Ribosomal inhibition and narrowspectrum antitubercular activity

Interference in ferredoxin oxidoreductase (PFOR) enzymedependent electron transfer reaction

Inhibition of mycobacterial cell wall methoxy mycolic acid and ketomycolic acid Class of peptide based natural antibacterial Inhibition of protein synthesis by agents produced by the bacterium Xenorhabdus ribosome-targeting mechanism. nematophila 
Table 7 Reported natural compounds with considerable antitubercular activity with minimum inhibitory concentration in micrograms per millilitre

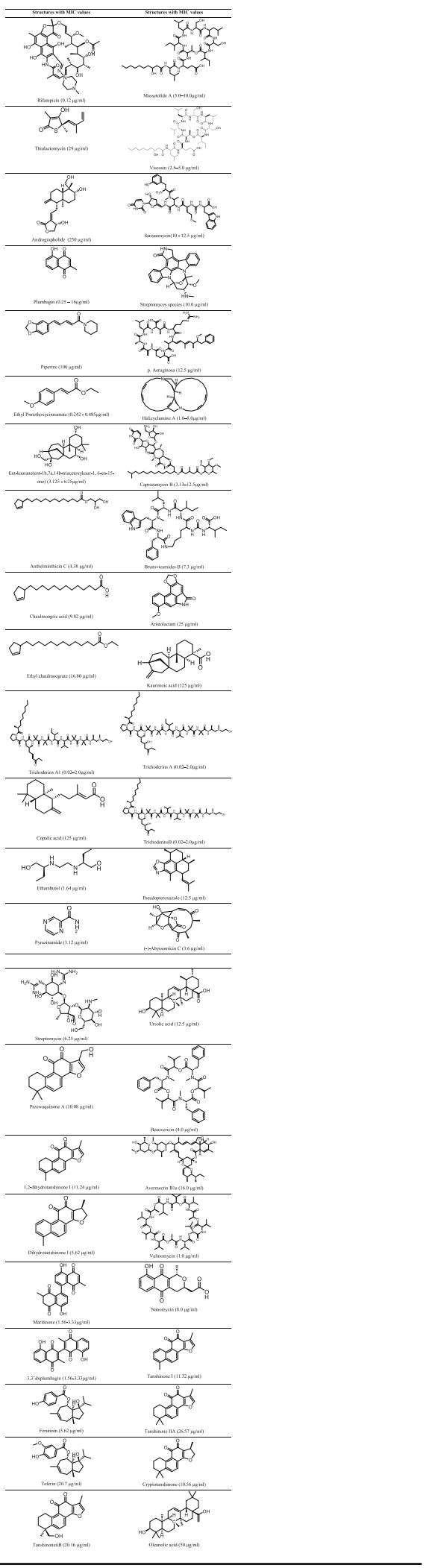

activation of Escherichia coli SOS DNA-damage response and error-prone DNA polymerases in all cells. Hence, the FDA approved the drug 'edaravone', administered along with antibiotic which resulted in decreased levels of ROS in E. coli population; thus, edaravone can down the mutations in the bacteria [77].

\section{Nanotheranostics}

Nanotheranostics are the novel drug delivery approach based on the integration of both diagnostic and therapeutic function in a unit drug delivery system, which is now extremely attracted for personalized medicine. Previously, there was very limited drug delivery approach to fight drug resistance in microbes and cancer.

\section{Antimicrobial nanotheranostics}

In recent time, a number of nanoparticle (NP) drug delivery approaches, including nanotheranostics, have been investigated and reported [78]. They revealed the antimicrobial efficacy of nanoparticles including silver NP, gold NP, bimetallic NP, copper oxide NP, iron oxide NP, zinc oxide NP, etc. In addition, liposomal nano formulations were also reported for antibiotics including amikacin and ciprofloxacin which are under clinical trials. Though the silver nanoparticles (AgNPs) have been known for broad-spectrum antibacterial property against drug-resistant bacteria, the mechanism was elusive. But in a recent study, the light-excited AgNPs induced protein aggregation in E. coli, which relied on the lightcatalysed oxidation of cellular proteins. It seems that AgNPs can absorb the photon energy and can transfer energy to the bacterial proteins, thus promoting the bacterial protein to undergo degradation and leading to death. Furthermore, the isobaric tags for relative and absolute quantification (iTRAQ)-based proteomics showed that the bacteria had failed to develop resistance to the light-excited nanoparticles [79].

\section{Anticancer nanotheranostics}

The co-encapsulated nanoparticles containing daunorubicin and glycyrrhizic acid significantly inhibited the growth of drug-resistant leukaemia cells and bypassed the drug resistance. It was also reported that the formulated nanoparticles enhanced the drug uptake in the resistant K562/A02 cells. Furthermore, the modified Pglycoprotein antibody on the nanoparticles has further increased the drug uptake in the leukaemia cells [80]. Still there are challenges in nanoparticle delivery to tumour cells, and they include the need for assessing the interactions of nano-antibiotics with cells, tissues and organs for dose optimization and for appropriate routes of drug delivery [81]. The biocompatibility of NPs need to be evaluated because NPs can enter through skin contact, ingestion, inhalation, oral and intravenous injection; 
hence, the appropriate in vivo models need to be used to understand the insights on their potential toxicity and metabolism [82].

\section{New drug targets and approaches}

The outcome of new antimicrobial drug with the conventional drug discovery approach is very slow and the future outcomes are also not optimistic. Hence, there is a need for reanalyzing the discovery strategy as integrative approach towards achieving new class of antibiotics and new antimicrobial adjuvants, but focusing on alternative validated targets [20, 21, 83]. Thus, antimicrobial adjuvants $[84,85]$ act as (a) efflux pumps inhibitors, (b) permeability enhancers, (c) virulence factor inhibitions, (d) transfer inhibitions and (e) anti-quorum sensing. The possible antimicrobial drug targets are discussed below.

\section{NagZ Protein}

It is a cytoplasm protein responsible for development of drug resistance in microbes through beta-lactamase expression, cell recycling process and biofilm formation. The NagZ protein is known as $N$-acetyl- $\beta$-d-glucosaminidase and plays a crucial role in the peptidoglycan recycling pathway of Gram-negative bacteria [86]. The product of NagZ protein, 1,6-anhydromuramoyl-peptide, is responsible for the induction $\beta$-lactam resistance in many bacteria and is induced by the expression of AmpC $\beta$-lactamase [87]. Hence, inhibitors of NagZ activity like PUGNAc, MM-124 (non-selective), EtBuPUG and MM-156 (selective) could suppress $\beta$-lactam antibiotic resistance in bacteria $[88,89]$.

\section{AmpG Protein}

It is only the permease class of protein present in the cell membrane of drug-resistant microbes and acting as signal transducer for beta-lactamase production and internalization of soluble muropeptide into cytoplasm. Other proteins such as AmpC and AmpD are present in the cytoplasm and they are involved only in the cell recycling process. Inhibition of AmpG will lead to depletion of beta-lactamase enzyme; thus, the design of AmpG inhibitors (fosfomycin) could be a better choice to suppress the release of beta-lactamase in microbes, and these agents can serve as more suitable antimicrobial adjuvants to $\beta$-lactam antibiotics [90]. In addition, the inhibition of AmpG proteins will lead to the termination of the cell wall recycling process; thus, the permeability of the cell wall can also be greatly enhanced. Hence, these agents could also serve as permeability enhancer to all potent antibiotics/fluoroquinolones [91]. The AmpG may be the more suitable drug target due to the proven mechanism of beta-lactamase expression in many drug-resistant bacteria and more reliable for its location (cell membrane) as compared to NagZ (cytoplasm), shown in Fig. 11.

\section{Polyphosphate kinase}

In bacteria, the synthesis of inorganic polyphosphate (Poly P) from ATP is catalysed by polyphosphate kinase (PPK). Three polyphosphate kinase enzymes including PPK1, PPK2 and PРК3 have been documented as responsible marker for the accumulation of inorganic polyphosphate in microbes including Mycobacterium tuberculosis through animal models [92]. Among all, the role of PPK2 has been well studied in the development of drug resistance, virulence and cell wall permeability to polar TB drugs. Hence, it would be beneficial to design a new small molecule as PPK2 inhibitors (NSC 35676, NSC 30205, NSC 345647 and NSC 9037) as adjuvant to the existing antibiotics and antitubercular drugs [93]. There are reports on small molecules of PPK2 inhibitors, increased antitubercular activity of isoniazid (8 fold) and polar drugs. Therefore, adding these PPK2 inhibitors as adjuvant to the existing anti-TB drugs or antibiotics would benefit the existing drug regimen for the cure of drug-resistant infections [94, 95].

\section{Cytochrome bc1 complex}

In all microbes, cytochrome bc1 complex (complex III) is responsible for mitochondrial respiratory chain in the intracellular metabolic pathways. Thus inhibition of cytochrome bc1 complex will lead to the depletion of ATP and results in bactericidal action. Several experts quoted that the cytochrome bc1 complex could be the most suitable target for MDR/XDR-TB among complex I to V. Complex III (Cytochrome bc1, Cytochrome c) is playing a critical role in the biochemical generation of ATP in Fig. 12. There are reports on inhibitors of cytochrome bc1 at Q site [96], e.g. lansoprazole [97], atovaquone [98, 99], antimycin [100], stigmatellin [101] and myxothiazole [102], where these inhibitors induced lethal effect to mycobacterium, by inhibiting electron transfer form Cyt b to Cyt c. Furthermore, there is no evidence for acquired mutation associated with mycobacterial cytochrome bc1 complex.

\section{Auto-inducers (Als)}

Auto-inducers are signalling molecules produced in microbial culture as a response to the change in microbial population density. Therefore, the density of quorumsensing bacterial cells is directly proportional to the concentration of the auto-inducers. Quorum sensing is the ability of bacteria to sense one another, which exists in both Gram-negative and Gram-positive bacteria. Through this quorum sensing, bacteria regulate variety of activities including symbiosis, virulence, motility, antibiotic production and biofilm formation [103]. 


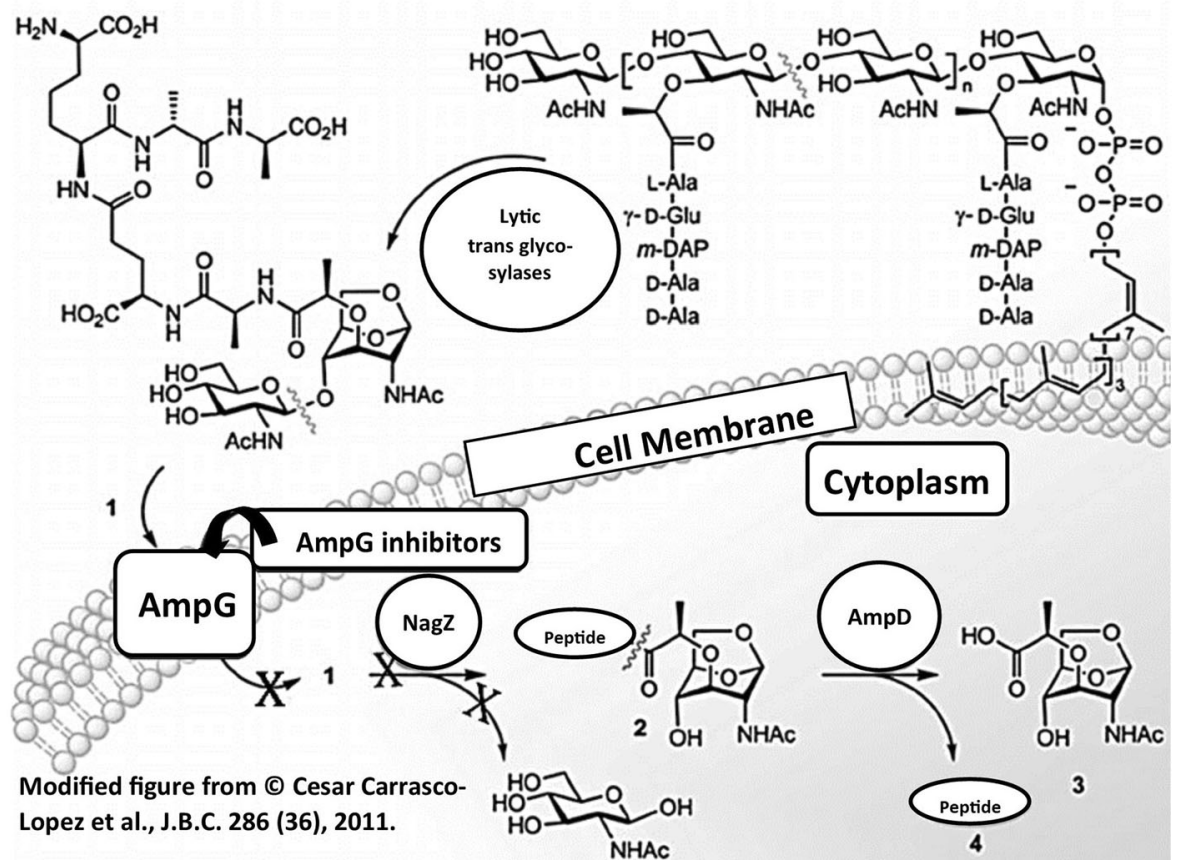

Fig. 11 Proposed mechanism for AmpG inhibitors which interfere in intracellular protein synthesis

Auto-inducers differ from species to species and allow the microbes to communicate within and between different species [104]. Three major types of auto-inducers (AIs) exist in most of the Gram-negative organisms, e.g. 4-nitro-pyridine-N-oxide (4-NPO), Acylated homoserine lactones (AHL), N-3-oxohexanoyl-L-homoserine lactones (AI-1).

Auto-inducing peptides (AIPs)

AIPs found in Gram-positive organisms are processed, modified and excreted by amino acids or short peptides

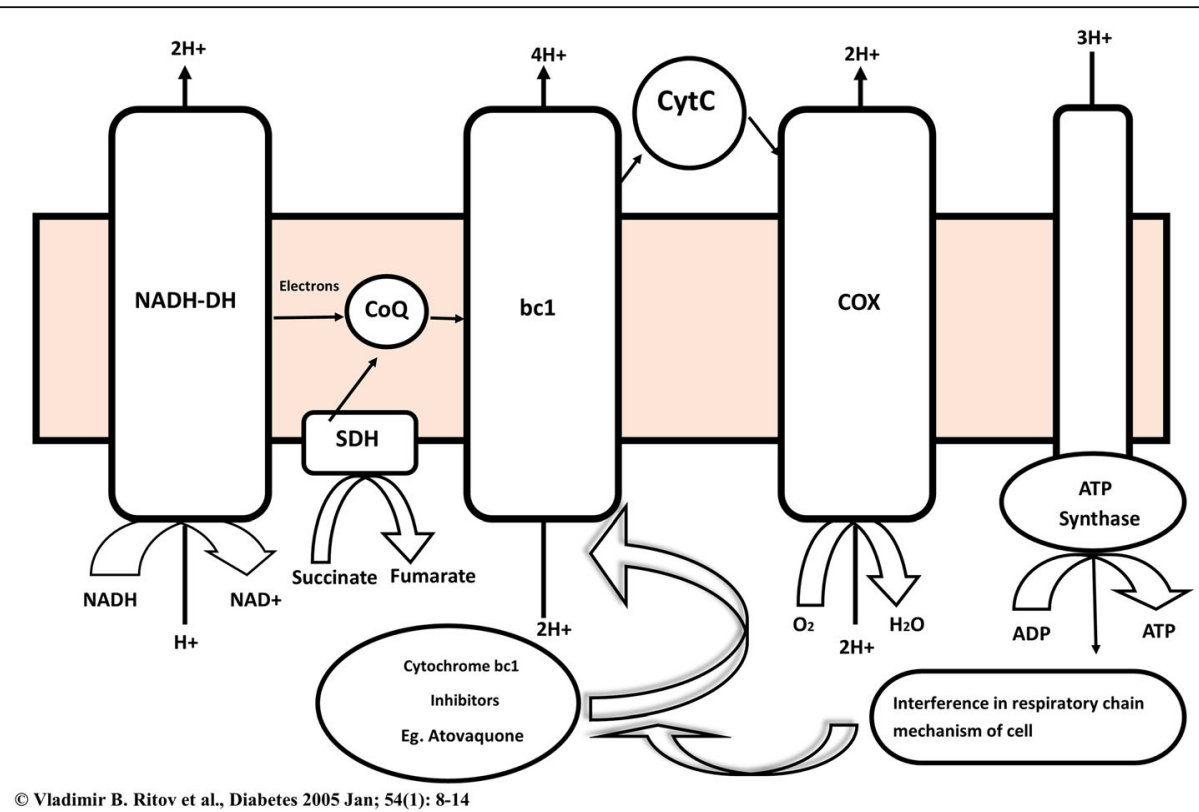

Fig. 12 Proposed mechanism for cytochrome bc1 inhibition which result in inhibition of ATP synthesis 
synthesized/processed/modified/excreted by the ATPbinding cassette export systems. AIP binds to the cell surface-bound histidine protein kinase that autophosphorylates which is a response regulator responsible for the activation of transcription of target genes.

\section{Auto-inducer-2 compounds}

AI-2 are derived furanones present in both Gramnegative and Gram-positive bacteria. As an example, LuxS (enzyme) produces 4, 5-dihydroxy-2, 3pentanedione (DPD) acylhomoserine lactones which are a forerunner of AI-2. This auto-inducer binds to LuxP protein to produce AI-2/LuxP complex. The complex binds to the membrane-bound histidine protein kinase. Further, signal transduction channels in multistep phosphorylation are similar to AIPs [105].

\section{LuxS and Quorum-sensing inhibitors (QSIs)}

They are derived from the information of AIs. QSIs act through the blocking of signal synthesis [106]. For example, LuxS is the target, and the inhibitors of LuxS could act as broad-spectrum antibiotics [107]. The other possible blockade strategies are targeting the autoinducer receptor site of the LuxR homologues, histidine protein kinase or Lsr transporter [108]. Additional approach for QSIs is to block the formation of active dimers (essential for binding and expression of target genes and enhancement of signal molecule degradation) [83]. Always the combination of both mechanisms will be more effective than a single mechanism approach. The reported molecules as QS inhibitors (QSI) are agrocinopine $\mathrm{B}$, furanone, Canavanine, norepinephrine, epinephrine, penicillic acid and patulin.

\section{TCST system}

The two-component signal transduction (TCST) systems are the primary means for coordinating responses to environmental changes in bacterium as similar to some plants, fungi, protozoa and archaea [106]. These systems generally comprise a receptor essential amino acid enzyme, histidine kinase (HK), that will react to an extracellular signal by phosphorylating cytoplasmic response regulator [109]. The most common inhibitors reportable so far are hydrophobic compounds that inhibit HKautokinase activity, noncompetitively with relevance to ATP $11[110,111]$.

\section{Division machinery targets}

The division machinery of bacteria can be a striking drug target, and seven or additional essential proteins are preserved virtually throughout the bacterial kingdom; however, these proteins are absent in humans. Examples, the polymerized filamenting temperaturesensitive mutant $\mathrm{Z}$ (FtsZ) recruits alternative cell proteins, together with FtsA, ZipA, FtsK, FtsQ, FtsL, FtsW,
FtsI and FtsN, resulting in the formation of a Z-ring and also the initiation of the complicated method of partitioning [105].

\section{1-Deoxy-D-xylulose-5-phosphate (DOXP) synthase}

The enzyme, 1-deoxy-D-xylulose-5-phosphate (DOXP) synthase is known to be inhibited by fosmidomycin (antibiotic from gram-positive bacterium). This enzyme is also profound in alternative, non-mevalonate pathway for the production of carotenoids, phytol, plastoquinone-9, isoprene and mono- and diterpenes [106]. Now, the enzymes of the 1-deoxy-D-xylulose 5phosphate (DOXP) and 2-C-methylerythritol 4phosphate (MEP) pathway were identified as targets for new herbicides and antibacterial drugs. Till today, no inhibitors for the DOXP synthase have been discovered. There are reports where clomazone degradation products showed inhibition on DOXP synthase [108].

\section{Enzymes of fatty acid synthesis}

FabH, FAabG, FAbI and FabF/B are essential enzymes in fatty acid (type II pathway) synthesis in microbes. They are extremely enticing targets for the development of antibacterial and antiparasitic compounds [108]. Two natural products specifically cerulenin and thiolactomycin inhibited the compressing or condensation enzymes FabH and FabF/B. Cerulenin shows selectivity on FabF/ $\mathrm{B}$, whereas thiolactomycin (TLM) and its analogues shows inhibition on FabH and FabF/B. Acyl group carrier protein synthesis (AcpS) is very important in the fatty synthesis in true bacterium or Mycobacterium. CoaD isozyme has additionally gained much importance in the medicinal drug design or antibacterial drug design target [109].

\section{MUR inhibitors}

The MurA (UDP-N-acetylglucosamine enolpyruvyl transferase) is a fundamental enzyme found in bacteria, responsible for transferring enolpyruvate (EP) from phosphoenolpyruvate (PEP) to uridine diphosphate $\mathrm{N}$ acetylglucosamine (UDP-GlcNAc). This step is the first biochemical in bacterial peptidoglycan synthesis. This MurA is conserved in bacteria, but not in human. Hence, this enzyme can be a drug target for antibacterial drug discovery. Furthermore, this target has been validated using fosfomycin (RWJ-3981, RWJ-110192 and RWJ-140998 are in trials) which is currently available in clinical use. This fosfomycin shows covalent binding to Cys115 in the MurA enzyme and thus interrupts the active site responsible for release of UDP-GlcNAcenoylpyruvate and ultimately leading to cell death [112]. 


\section{Combination therapy and antibiotic-free treatment to tackle drug resistance}

In 2018, researchers at the University of California, Los Angeles (UCLA) stated that combining four or five antibiotics stopped or slowed down the severity of drugresistant bacterial infections. The team used a mathematical model called as MAGIC (mathematical analysis of general interactions of the components), which has enabled them to anticipate their results of antibiotic combination and the team suggested about 8000 theoretical combinations [113]. A new animal experiment has shown the efficacy of bacterial toxin-grabbing nanoparticles (Dutch biotech company), which involved the use of machinery from phages (bacteria-killing virus) to target the drug-resistant Staphylococcus aureus.

\section{Conclusion}

Overall, the amount of advancement in research to curtail the antimicrobial resistance is quite satisfactory. The various advancements in drug discovery are gene paradox, transposon mutagenesis, interfering vitamin and fatty acid biosynthesis, use of non-conventional growth media and host model for drug screening and targeting the quorum-sensing virulence pathway. Many researchers emphasized that drug target of resistant microbes which are essential in fatty acid biosynthesis, vitamin biosynthesis and respiratory mechanism in microbes would be more beneficial. In the literature, we found that there has been lot of natural hit molecules which are structurally diverged and have proven their acceptable antimicrobial activity on virulent species including Mycobacterium tuberculosis. These molecules have to be further investigated to enhance their antimicrobial efficacy in drug-resistant microbes or to assess their suitability as co-administered agent with standard regimen. It is highly recommended to retrieve the life of existing antibiotics through antimicrobial adjuvant discovery. Hence, it is highly recommended to execute the anti-drug resistance research as integrated approach where both molecular and genetic research needs to be the integrative objective of drug discovery. The hope for new hit drugs to fight drug resistance is not optimistic due to existing discovery void between genetic and molecule research and lack of validated drug targets. Overall, we conclude that this is time to accelerate new drug discovery research with advanced genetic approaches instead of conventional blind screening.

\footnotetext{
Abbreviations

MDR: Multidrug resistance; XDR: Extensively drug-resistant; MRSA: Methicillinresistant Staphylococcus aureus; VRSA: Vancomycin-resistant Staphylococcus aureus; CRE: Carbapenem-resistant Enterobacteriaceae; HSCT: Hematopoietic stem cell transplant; ABC: ATP-binding cassette; MFS: Major facilitator superfamily; OMP: Outer membrane protein; ACTs: Artemisinin combinational therapies; PfCRT: P. falciparum chloroquine-resistant transporter; oAMT: Oral artemisinin-based monotherapy; IAV: Influenza A virus; HSV: Herpes simplex
}

virus; HCMV: Human cytomegalovirus; HBV: Hepatitis B virus; HCV: Hepatitis C virus; HA: Hemagglutinin; NA: Neuraminidase; WTA: Wall teichoic acid; NGS: Next-generation sequencing; AMPs: Antimicrobial peptides; HDPs: Host defence peptides; ROS: Reactive oxygen species; iTRAQ: Isobaric tags for relative and absolute quantification; PPK: Polyphosphate kinase; AHL: Acylatedhomoserine lactones; AIPs: Auto-inducing peptides; QSIs: Quorum-sensing inhibitors; TCST: Two-component signal transduction; HK: Histidine kinase; FtsZ: Filamenting temperature-sensitive mutant Z; DOXP: 1-Deoxy-D-xylulose-5-phosphate; MEP: 2-C-methylerythritol 4phosphate; TLM: Thiolactomycin; AcpS: Acyl group carrier protein synthesis; EP: Enolpyruvate

\section{Acknowledgements}

This communication was supported by the DST-FIST Laboratory of Raghavendra Institute of Pharmaceutical Education and Research (RIPER), Anantapur

(AP), India, funded by Department of Science and Technology, Govt. of India.

\section{Authors' contributions}

RP contributed to the design and concept for this manuscript. SS, VN, NC, PR and CP drafted the work. SC contributed in writing and revision of the manuscript. VK collected chemical structures, other information and compiled tables and presented precisely. All authors read and approved the final manuscript.

Funding

No funding is received

Availability of data and materials

NA

Ethics approval and consent to participate

NA

Consent for publication

NA

\section{Competing interests}

The authors declare that they have no competing interests.

\section{Author details}

${ }^{1}$ RERDS-CPR, Raghavendra Institute of Pharmaceutical Education and Research (RIPER)-Autonomous, Anantapur, Andhra Pradesh, India. ${ }^{2}$ ICMR-National Institute of Research in Tuberculosis, Chennai, Tamilnadu, India.

Received: 11 September 2020 Accepted: 3 February 2021

Published online: 03 March 2021

\section{References}

1. Gerard D (2016) Antibiotic adjuvants: rescuing antibiotics from resistance. Trends Microbiol 24:862-871

2. David B (2015) Antibiotic resistance breakers: can repurposed drugs fill the antibiotic discovery void? Nat Rev Drug Discov 14:821-832

3. World Health Organization (WHO) (2019) New report calls for urgent action to avert antimicrobial resistance crisis, Geneva Available at https://www. who.int/news-room/detail/29-04-2019-new-report-calls-for-urgent-actionto-avert-antimicrobial-resistance-crisis (accessed April 29 2019)

4. World Health Organization (WHO) (2018) Antimicrobial resistance, Geneva Available at https://www.who.int/news-room/fact-sheets/detail/antimicrobia I-resistance (accessed February 15 2018)

5. World Health Organization (WHO) (2016) Global tuberculosis report 2016. Available at www.who.int/tb/publications/global_report (accessed April 19 2019).

6. Prasad R, Goffeau A (2012) Yeast ATP-binding cassette transporters conferring multidrug resistance. Annu. Rev. Microbiol. 66:39-63

7. General Assembly of the United Nations (2016) High-level meeting on antimicrobial resistance. Available at http://www.un.org/pga/71/event-latest/ high-level-meeting-on-antimicrobial-resistance (accessed July 21 2019).

8. Arzanlou M, Chai WC, Venter H (2017) Intrinsic, adaptive and acquired antimicrobial resistance in Gram-negative bacteria. Essays Biochem 61:49-59 
9. Konstantinos M, Wendy E, Kaman GE, Mara S, John PH (2018) Challenges in identifying antibiotic resistance targets for point-of-care diagnostics in general practice. Future Microbiol 13:1157-1164

10. Center for Disease Control and Prevention (2019) Antibiotic resistance threats in the United States. Department of Health and Human Services, United States Available at https://www.cdc.gov/drugresistance/pdf/threatsreport/2019-ar-threats-report-508.pdf (accessed August 12 2019)

11. Zahreddine $\mathrm{H}$, Borden $\mathrm{KL}$ (2013) Mechanisms and insights into drug resistance in cancer. Front Pharmacol 4:1-8

12. Elizabeth P, Parjit K (2018) Antibiotic resistance mechanisms in bacteria: relationships between resistance determinants of antibiotic producers, environmental bacteria, and clinical pathogens. Front Microbiol 30:1-21

13. Lia DA, Rosella C, Giovanni S, Emanuele P, Antonio S, Migliori GB (2015) New anti-tuberculosis drugs and regimens. ERJ Open Res 1:1-15

14. Voniatis C, Migliori GB (2014) M. tuberculosis elimination: dream or reality? The case of Cyprus. EUR Respir J 44:543-546

15. Charles DW, Rajesh G, Norbet H (2015) Long-term mortality assessment of multidrug-resistant tuberculosis patients treated with delamanid. EUR Respir J 45:1498-1501

16. Diacon AH, Donald PR, Pym A, Grobusch M, Patentia RF, Mahanyele R, Bantubani N, Narasimooloo R, De Marez T, Heeswijk RV, Lounis N, Meyvisch P, Andries K, McNeeley DF (2012) Randomized pilot trial of eight weeks of bedaquiline (TMC207) treatment for multidrug-resistant tuberculosis: long term outcome, tolerability, and effect on emergence of drug resistance. Antimicrob Agents Chemother 56:3271-3276

17. Andréanne L, Caroline SF, Svetlana S, Anthony VJ, Piton NM, Andrej B, Dirk AL, Adrie JCS, Kevin P, Vadim AM (2020) New 2-Ethylthio-4-

methylaminoquinazoline derivatives inhibiting two subunits of cytochrome bc1 in Mycobacterium tuberculosis. PLOS Pathog 16:1-19

18. Falzon D, Gandhi N, Migliori GB, Sotgiu G, Cox HS, Holtz TH, Hollm DMG, Keshavjee S, DeRiemer K, Centis R, Dambrosio L, Lange CG, Bauer M, Menzies D (2013) Collaborative group for meta-analysis of individual patient data in MDR-TB. Resistance to fluoroquinolones and second-line injectable drugs: impact on multidrug-resistant TB outcomes. EUR Respir J 42:156-168

19. Zumla Al, Schito M, Maeurer M (2014) Advancing the portfolio of tuberculosis diagnostics, drugs, biomarkers, and vaccines. Lancet Infect Dis 14:7-9

20. Arora G, Tiwari P, Mandal RS, Gupta A, Sharma D, Saha S, Singh R (2014) High throughput screen identifies small molecule inhibitors specific for Mycobacterium tuberculosis phosphoserine phosphatase. J Biol Chem 289: 25149-25165

21. Shum KT, Lui ELH, Wong SCK, Yeung P, Sam L (2011) Aptamer-mediated inhibition of Mycobacterium tuberculosis polyphosphate kinase 2. Biochemistry 50:3261-3271

22. Brown GD, Denning DW, Gow NAR, Levitz SM, Netea MG, White TC (2012) Hidden killers: human fungal infections. Sci Transl Med 4:1-9

23. Wisplinghoff $H$, Bischoff $T$, Tallent SM, Seifert $H$, Wenzel RP, Edmond MB (2019) Nosocomial bloodstream infections in US hospitals: analysis of 24,179 cases from a prospective nationwide surveillance study. Clin Infect Dis 39: 309-317

24. Kontoyiannis DP, Marr KA, Park BJ, Alexander BD, Anaissie EJ, Walsh TJ (2010) Prospective surveillance for invasive fungal infections in hematopoietic stem cell transplant recipients, 2001-2006: overview of the transplant-associated infection surveillance network (TRANSNET) database. Clin Infect Dis 50:1091-1100

25. Gaur M, Puri N, Manoharlal R, Rai V, Mukhopadhayay G, Choudhury D, Prasad R (2008) MFS transportome of the human pathogenic yeast Candida albicans. BMC Genom 9:1-12

26. Paulsen IT, Sliwinski MK, Nelissen B, Goffeau A, Saier MH (1998) Unified inventory of established and putative transporters encoded within the complete genome of Saccharomyces cerevisiae. FEBS Lett 430:116-125

27. Gbelska Y, Krijger JJ, Breunig KD (2006) Evolution of gene families: the multidrug resistance transporter genes in five related yeast species. FEMS Yeast Res. 6:345-355

28. Kelly S, Lamb D, Corran A, Baldwin B, Kelly D (1995) Mode of action and resistance to azole antifungals associated with the formation of 14alphamethylergosta-8, 24(28)-dien-3ß,6a-diol. Biochem Biophys Res Commun 207 910-915

29. Eddouzi J, Parker JE, Vale-Silva LA, Coste A, Ischer F, Kelly S (2013) Molecular mechanisms of drug resistance in clinical Candida species isolated from Tunisian hospitals. Antimicrob Agents Chemother 57:3182-3193
30. Martel CM, Parker JE, Bader O, Weig M, Gross U, Warrilow AGS (2010) Identification and characterization of four azole-resistant erg3 mutants of Candida albicans. Antimicrob Agents Chemother 54:4527-4533

31. Chau AS, Gurnani M, Hawkinson R, Laverdiere M, Cacciapuoti A, McNicholas PM (2005) Inactivation of sterol delta ${ }^{5,6}$-desaturase attenuates virulence in Candida albicans. Antimicrob Agents Chemother 49:3646-3651

32. Morio F, Pagniez F, Lacroix C, Miegeville M, Le Pape P (2012) Amino acid substitutions in the Candida albicans sterol $\Delta^{5,6}$-desaturase (Erg3p) confer azole resistance: characterization of two novel mutants with impaired virulence. J Antimicrob Chemother 67:2131-2138

33. Korenromp EL, Williams BG, Gouws E, Dye C, Snow RW (2003) Measurement of trends in childhood malaria mortality in Africa: an assessment of progress toward targets based on verbal autopsy. Lancet Infect Dis 3:349-358

34. Marsh K (1998) Malaria disaster in Africa. Lancet 352:924-925

35. Nosten F (2000) Effects of artesunate-mefloquine combination on incidence of Plasmodium falciparum malaria and mefloquine resistance in western Thailand: a prospective study. Lancet 356:297-302

36. Plowe CV (2003) Monitoring antimalarial drug resistance: making the most of the tools at hand. J. Exp. Biol. 206:3745-3752

37. Mehta K, Fok JY (2009) Targeting transglutaminase-2 to overcome chemoresistance in cancer cells. Drug Resistance in Cancer Cells, 1st edn. SpringerVerlag, New York, pp 95-114

38. Holohan C, Van Schaeybroeck S, Longley DB, Johnston PG (2013) Cancer drug resistance: an evolving paradigm. Nat Rev Cancer 13:714-726

39. World Health Organization (WHO) (2018) Responding to antimalarial drug resistance, Geneva Available at https://www.who.int/malaria/areas/drug_ resistance/overview/en/ (accessed April 20 2018)

40. Hernandez RC, Jacome R, Vidal YL, Ponce de Leon S (2017) Are RNA Viruses Candidate Agents for the Next Global Pandemic? A Review. ILAR J 58:343358. https://doi.org/10.1093/ilar/ilX026

41. Simmonds $P$ (2004) Genetic diversity and evolution of hepatitis C virus - 15 years on. J Gen Virol 85:3173-3178

42. Chen R, Holmes EC (2010) Hitchhiking and the population genetic structure of avian influenza virus. J Mol Evol 70:98-105

43. Andrei G (2013) Heterogeneity and evolution of thymidine kinase and DNA polymerase mutants of herpes simplex virus type 1: Implications for Antiviral Therapy. JID 207:295-305

44. Renzette N, Daniel RC, Konstantin BZ, Ping L, Glen RG, Daniel A, Alyssa JP, Evelyn AK, Daniel NB, Yu-Ping PJ, Jensen D, Celia AS, Timothy FK, Robert WF, Jennifer PW (2014) Evolution of the influenza A virus genome during development of oseltamivir resisitance in vitro. J Virol 88:272-281

45. Gott M (2017) The distinct contributions of fitness and genetic barrier to the development of antiviral drug resistance. Curr Opin Virol 2:644-650

46. Bang KB, Kim HJ (2014) Management of antiviral drug resistance in chronic hepatitis B. World J Gastroenterol 20:11641-11646

47. Andrew RJ, Jennifer LR, Aprilfawn W, Robert E, Andrei O, Tomoya B, Hirotada M, Scott AL, Bernhard P, Sanjay A (2006) Experimental and computational assessment of conditionally essential genes in Escherichia coli. J Bacteriol 188:8259-8271

48. Delia MA, Millar KE, Bhavsar AP, Tomljenovic AM, Hutter B, Schaab C, Moreno HG, Brown ED (2009) Probing teichoic acid genetics with bioactive molecules reveals new interactions among diverse processes in bacterial cell wall biogenesis. Chem Biol 16:548-556

49. Autret N, Charbit A (2005) Lessons from signature-tagged mutagenesis on the infectious mechanisms of pathogenic bacteria. FEMS Microbiology Reviews. 29:703-717

50. Hensel M, Shea JE, Gleeson C, Jones MD, Dalton E (1995) Simultaneous identification of bacterial virulence genes by negative selection. Science 269:400-403

51. Nichols RJ, Sen S, Choo YJ, Beltrao P, Zietek M, Chaba R, Lee S, Kazmierczak KM, Lee KJ, Wong A, Shales M, Lovett S, Winkler ME, Krogan NJ, Typas A, Gross CA (2011) Phenotypic landscape of a bacterial cell. Cell. 144:143-156

52. Opijnen VT, Camilli A (2013) Transposon insertion sequencing: a new tool for systems-level analysis of microorganisms. Nat Rev Microbiol 11:435-442

53. Turner KH, Wessel AK, Palmer GC, Murray JL, Whiteley M (2015) Essential genome of Pseudomonas aeruginosa in cystic fibrosis sputum. Proc Natl Acad Sci U S A 112:4110-4115

54. Haas H (2014) Fungal siderophore metabolism with a focus on Aspergillus fumigatus. Natural. Product Reports. 31:1266-1276 
55. Huh WK, Kim ST, Kim H, Jeong G, Kang SO (2001) Deficiency of Derythroascorbic acid attenuates hyphal growth and virulence of Candida albicans. Infection and Immunity 69:3939-3946

56. Paul D, Chatterjee A, Begley TP, Ealick SE (2010) Domain organization in Candida glabrata THI6, a bifunctional enzyme required for thiamin biosynthesis in eukaryotes. Biochemistry 49:9922-9934

57. Fahnoe KC, Mark EF, Glenn G, Veerabahu S, Che Y, Andrew PT (2012) Non-traditional antibacterial screening approaches for the identification of novel inhibitors of the glyoxylate shunt in Gram-negative pathogens. PLOS One 7:1-7

58. Zlitni S, Ferruccio LF, Brown ED (2013) Metabolic suppression identifies new antibacterial inhibitors under nutrient limitation. Nat Chem Biol. 9:796-804

59. Starkey M (2014) Identification of anti-virulence compounds that disrupt quorum-sensing regulated acute and persistent pathogenicity. PLoS Pathogen 10:1-18

60. Pethe K, Bifani P, Jang J, Kang S, Park S, Ahn S, Jiricek J, Jung J, Jeon HK, Cechetto J, Christophe T, Lee H, Kempf MP (2013) Discovery of Q203, a potent clinical candidate for the treatment of tuberculosis. Nat Med 19: 1157-1160

61. Delia MA, Pereira BMP (2009) Are essential genes really essential? Trends Microbiol 17:433-438

62. Liu A, Tran L, Becket E, Lee K, Chinn L, Park E, Tran K, Miller JH (2010) Antibiotic sensitivity profiles determined with an Escherichia coli gene knockout collection: generating an antibiotic bar code. Antimicrobial Agents and Chemotherapy. 54:1393-1403

63. El-Ghachi M, Bouhss A, Blanot D, Mengin-Lecreulx D (2004) The bacA gene of Escherichia coli encodes an undecaprenyl pyrophosphate phosphatase activity. J Biol Chem 279:30106-30113

64. Pathania R, Zlitni S, Barker C, Das R, Gerritsma DA, Lebert J, Awuah E, Melacini G, Capretta FA, Brown ED (2009) Chemical genomics in Escherichia coli identifies an inhibitor of bacterial lipoprotein targeting. Nature Chemical Biology. 5:849-856

65. Taylor PL, Rossi L, De Pascale G, Wright GD (2012) A forward chemical screen identifies antibiotic adjuvants in Escherichia coli. ACS Chem Biol 7: 1547-1555

66. Laaveri T, Sterne J, Rombo L, Kantele A (2016) Systematic review of loperamide: No proof of antibiotics being superior to loperamide in treatment of mild/moderate travellers' diarrhoea. Travel Med Infect Dis. 14: 299-312

67. Borisy AA, Peter JE, Nicole WH, Margaret SL, Joseph L, Roydon EP, Serbedzija G, Zimmermann GR, Michael AF, Brent RS, Curtis TK (2003) Systematic discovery of multicomponent therapeutics. Proc Natl Acad Sci U S A 100: 7977-7982

68. King AM, Reid-Yu SA, Wang W, King DT, De Pascale G, Strynadka NC, Walsh TR, Coombes BK, Wright GD (2014) Aspergillomarasmine A overcomes metallo- $\beta$-lactamase antibiotic resistance. Nature. 510:503-506

69. Ejim L, Farha MA, Falconer SB, Wildenhain J, Coombes BK, Tyers M (2011) Combinations of antibiotics and non-antibiotic drugs enhance antimicrobial efficacy. Nat Chem Biol 7:348-350

70. Crick C (1970) Central dogma of molecular biology. Nature 227:561-563

71. Khaledi A, Schniederjans M, Pohl S, Rainer R, Bodenhofer U, Xia B, Klawonn F, Bruchmann S, Preusse M, Eckweiler D, Dotsch A, Haussler S (2016) Transcriptome profiling of antimicrobial resistance in Pseudomonas aeruginosa. Antimicrob Agents Chemother 60:4722-4733

72. Michael RH, Heidi A (2018) Can light-based approaches overcome antimicrobial resistance? Drug Dev. Res 80:48-67

73. Maria GFC, Bernegossi J, Marise de Freitas L, Fontana CR, Chorilli M (2016) Nanotechnology-based drug delivery systems for photodynamic therapy of cancer: a review. Molecules 21:342. https://doi.org/10.3390/ molecules21030342

74. Amram M (2000) Peptide-based antibiotics: a potential answer to raging antimicrobial resistance. Drug Dev Res 50:440-447

75. Lei J, Lichun S, Huang S, Chenhong Z, Li P, He J, Vienna M, David HC, He Q (2019) The antimicrobial peptides and their potential clinical applications. Am J Transl Res 11:3919-3931

76. Hye Been K, Jiwon S (2019) Antimicrobial peptides under clinical investigation. Peptide Sci:e24122. https://doi.org/10.1002/pep2.24122

77. John PP, Libertad GV, Yin Z, Ohad LE, Anthony ZW, Jingjing L, Jun X, Qian M, Devon MF, Julia B, Robert HA, Christophe HD (2019) Gamblers: an antibiotic-induced evolvable cell subpopulation differentiated by reactiveoxygen-induced general stress response. Mol Cell 74:785-800
78. Pedro VB, Matthew PM, Andreia C, Ferreira AD, Niamh MM, Marta M, Alexandra RF (2018) Nano-strategies to fight multidrug resistant bacteria - a battle of the titans. Front Microbiol 9:1441-1453

79. Tianyuan S, Qiuxia W, Zhen W, Gong Z, Xuesong S, Qing YH (2019) Photocatalytic protein damage by silver nanoparticles circumvents bacterial stress response and multidrug resistance. Physiol Mol Biol Plants 4:1-12

80. Liuliu Z, Huayun Z, Yu G, Xiaohua W, Pingping W (2019) Dual drug-loaded PLA nanoparticles bypassing drug resistance for improved leukemia therapy. J Nanopart Res 21:83-88

81. Bao W, Liu R, Wang Y (2015) PLGA-PLL-PEG-Tf-based targeted nanoparticles drug delivery system enhance antitumor efficacy via intrinsic apoptosis pathway. Int J Nanomed 10:557-566

82. Sinha R, Kim GJ, Nie S, Shin DM (2006) Nanotechnology in cancer therapeutics: bioconjugated nanoparticles for drug delivery. Mol. Cancer Ther. 5:1909-1917

83. Chuang YM, Belchis DA, Karakousis PC (2013) The polyphosphate kinase gene ppk2 is required for Mycobacterium tuberculosis inorganic polyphosphate regulation and virulence. Microbiology 4:1-9

84. Chuang M, Nirmalya B, Dalin R, Harvey R, Joel SB, Petros CK (2015) Deficiency of the novel exopolyphosphatase Rv1026/PPX2 leads to metabolic downshift and altered cell wall permeability in Mycobacterium tuberculosis. Microbiol 6:1-15

85. FatmaAbdelaziz A, Mohamed El-Behedy E, Heba Ali M (2008) New targets for antibacterial agents. Biotechnol Mol Biol Rev 3:46-57

86. Balcewich MD, Stubbs KA, He Y, James TW, Davies GJ, Vocadlo DJ, Mark BL (2009) Insight into a strategy for attenuating AmpC-mediated beta-lactam resistance: structural basis for selective inhibition of the glycoside hydrolase NagZ. Protein Science. 18:1541-1551

87. Boudreau MA, Fisher JF, Mobashery S (2012) Messenger functions of the bacterial cell wall-derived muropeptides. Biochemistry. 51:2974-2990

88. Yi-Wei H, Rouh-Mei H, Cheng-Wen L, Tung-Ching C, Tsuey-Ching Y (2012) NagZ-Dependent and NagZ-independent mechanisms for $\beta$-lactamase expression in Stenotrophomonas maltophilia. Antimicrob Agents Chemother 56:1936-1941

89. Grishma V, Stubbs KA, Jerome D, Bleriot Y, David JV, Brian LM (2017) Conformational flexibility of the glycosidase NagZ allows it to bind structurally diverse inhibitors to suppress $\beta$-lactam antibiotic resistance. Protein Sci 26:1161-1170. https://doi.org/10.1002/pro.3166

90. Korfmann G, Sanders CC (1989) AmpG is essential for high-level expression of AmpC $\beta$ - lactamase in Enterobacter cloacae. Antimicrob Agents Chemother 33:1946-1951

91. Mark BL, Vocadlo DJ, Oliver A (2011) Providing B-lactams a helping hand: Targeting the AmpC $\beta$-lactamase induction pathway. Future Microbiol 6: 1415-1427

92. Nocek B, Kochinyan S, Proudfoot M, Brown G, Evdokimova E, Osipiuk J, Edwards AM, Savchenko A, Joachimiak A, Yakuninm F (2008) Polyphosphate-dependent synthesis of ATP and ADP by the family-2 polyphosphate kinases in bacteria. Proc Natl Acad Sci U S A 105:1773017735

93. Singh M, Tiwari P, Arora G, Agarwal S, Kidwai S, Singh R (2016) Establishing virulence associated polyphosphate kinase 2 as a drug target for Mycobacterium tuberculosis. Sci Rep 6:1-13

94. Singh R, Singh M, Arora G, Kumar S, Tiwari P, Kidwai S (2013) Polyphosphate deficiency in Mycobacterium tuberculosis is associated with enhanced drug susceptibility and impaired growth in guinea pigs. J Bacteriol 195:2839-2851

95. Zhang H, Ishige K, Kornberg A (2002) A polyphosphate kinase (PPK2) widely conserved in bacteria. Proc Natl Acad Sci U S A 99:16678-16683

96. Arkadiusz B, Robert E, Artur O (2018) Functional flexibility of electron flow between quinol oxidation Qo site of cytochrome bc1 and cytochrome c revealed by combinatory effects of mutations in cytochrome $b$, iron-sulfur protein and cytochrome c1. Biochimica et Biophysica Acta Bioenergetics 1859:754-761

97. Jan R, Anthony V, Claudia S, Philippe B, Florence P, Andrej B, Stewart TC (2015) Lansoprazole is an antituberculous prodrug targeting cytochrome bc1. Nat Commun 6:7659

98. Dominic B, Wei-Chun K, Carola H (2014) Structural analysis of atovaquoneinhibited cytochrome bc1 complex reveals the molecular basis of antimalarial drug action. Nat Commun 5:4029

99. Michael WM, Elisabeth D, Maria Valkova V, Jason WC, Michael TM, Fevzi D, Akhil BV (2005) Uncovering the molecular mode of action of the 
antimalarial drug atovaquone using a bacterial system. J Biol Chem 280: 27458-27465

100. Li-shar H, David C, Eric YT, Edward AB (2005) Binding of the respiratory chain inhibitor antimycin to the mitochondrial bc1 complex: a new crystal structure reveals an altered intramolecular hydrogen-bonding pattern. J Mol Biol 351:573-597

101. Georg T, Brigitte K, Hans R, Gerhard H (1984) The mode of action of stigmatellin, a new inhibitor of the cytochrome bcl segment of the respiratory chain. Biochimica et Biophysica Acta 765:227-235

102. Steven W, Meinhardt A (1982) R. Crofts. The site and mechanism of action of myxothiazol as an inhibitor of electron transfer in Rhodopseudomonas sphaeroides. FEBS Lett 149:217-222

103. Burkhard AH, Martin S (2015) Core principles of bacterial autoinducer systems. Microbiol Mol Biol Rev 79:153-169

104. Decho AW, Visscher PT, Ferry J, Kawaguchi T, He L, Przekop KM, Norma RS, Reid RP (2009) Autoinducers extracted from microbial matsreveal a surprising diversity of $\mathrm{N}$-acylhomoserine lactones (AHLs) and abundance changes that may relate to diel pH. Environ Microbiol 11:409-420

105. Hentzer M, Wu H, Andersen JB, Riedel K, Rasmussen TB, Bagge N, Kumar N, Schembri MA, Song ZJ, Kristoffersen P, Manefield M, Costerton JW, Molin S, Eberl L, Steinberg P, Kjelleberg S, Hoiby N, Givskov M (2003) Attenuation of Pseudomonas aeruginosa virulence by quorum sensing inhibitors. EMBO J 22:3803-3815

106. Brynildsen MP, Winkler JA, Spina CS, Macdonald IC, Collins JJ (2013) Potentiating antibacterial activity by predictably enhancing endogenous microbial ROS production. Nat. Biotechnol. 31:160-165

107. Rajni K, Shashikant R (2019) In bacterial cell division machinery: an insight for development of new antibacterial agent. In: Kumar S, Egbuna C (eds) Phytochemistry: An in-silico and in-vitro Update. Springer Nature, pp 109132

108. Rohmer M, Grosdemange BC, Seemann M, Tritsch D (2004) Isoprenoid biosynthesis as a novel target for antibacterial and antiparasitic drugs. Curr Opin Investigational New Drugs 5:154-162

109. Kuntz L, Tritsch D, Grosdemange BC, Hemmerlin A, Willem A, Bach TJ, Rohmer M (2005) Isoprenoid biosynthesis as a target for antibacterial and antiparasitic drugs: phosphonohydroxamic acids as inhibitors of deoxyxylulose phosphate reducto-isomerase. Biochem J 386:127-135

110. Izard TA (2002) The crystal structures of phosphopantetheineadenylyltransferase with bound substrates reveal the enzyme's catalytic mechanism. J Mol Biol 315:487-495

111. Izard TA (2003) Novel adenylate binding site confers phosphopantetheineadenylyltransferase interactions with Coenzyme. Bacteriol 185:4074-4080

112. Marko Juki C, Stanislav G, Matej S (2019) Reaching toward underexplored targets in antibacterial. Drug Dev Res 80:6-10

113. Elif T, Cynthia W, Tina MK, Singh N, Mauricio CL, Robert D, Van MS, Pamela JY (2018) Prevalence and patterns of higher-order drug interactions in Escherichia coli. npj Syst Biol Appl 4:31

\section{Publisher's Note}

Springer Nature remains neutral with regard to jurisdictional claims in published maps and institutional affiliations.

\section{Submit your manuscript to a SpringerOpen ${ }^{\circ}$ journal and benefit from:}

- Convenient online submission

- Rigorous peer review

- Open access: articles freely available online

- High visibility within the field

- Retaining the copyright to your article

Submit your next manuscript at $\boldsymbol{\nabla}$ springeropen.com 